\title{
Comparison of Two Mechanics-Based Methods for Simplified Structural Analysis in Vulnerability Assessment
}

\author{
H. Crowley, ${ }^{1}$ B. Borzi, ${ }^{1}$ R. Pinho, ${ }^{2}$ M. Colombi, ${ }^{1}$ and M. Onida ${ }^{1}$ \\ ${ }^{1}$ European Centre for Training and Research in Earthquake Engineering (EUCENTRE), Via Ferrata 1, 27100 Pavia, Italy \\ ${ }^{2}$ Dipartimento di Meccanica Strutturale, Università degli Studi di Pavia, Via Ferrata 1, 27100 Pavia, Italy
}

Correspondence should be addressed to H. Crowley, helen.crowley@eucentre.it

Received 8 April 2008; Accepted 28 June 2008

Recommended by Amr Elnashai

\begin{abstract}
Analytical vulnerability assessment methods should ideally be validated or verified by comparing their damage predictions with actual observed damage data. However, there are a number of difficulties related to the comparison of analytical damage predictions with observed damage; for example, there are large uncertainties related to the prediction of the ground motions to which the damaged buildings have been subjected. Until such problems can be resolved, it is worthwhile considering the mechanics of simplified analytical vulnerability assessment methods and validating this part of the methodology through comparisons with detailed structural models. This paper looks at two mechanics-based vulnerability assessment methods (DBELA and SP-BELA) and compares the nonlinear static response predicted with these methods with finite elements-based nonlinear analyses of prototype buildings. A comparison of the predicted response of urban populations of buildings using the two methods is then carried out, and the influence of these differences on vulnerability curves is studied.
\end{abstract}

Copyright $($ ) $2008 \mathrm{H}$. Crowley et al. This is an open access article distributed under the Creative Commons Attribution License, which permits unrestricted use, distribution, and reproduction in any medium, provided the original work is properly cited.

\section{Introduction}

The vulnerability of reinforced concrete buildings has been the focus of much research over the past 30 years (e.g., [1]), with methods varying from those based on the observed damage of buildings in past earthquakes to detailed analytical studies of prototype buildings under seismic action. The advantage of empirical vulnerability assessment methods, based on observed damage data for a given type of construction, is that they convey a high level of confidence of what might be the damage to that building type under similar levels of future ground motions. However, there are a number of disadvantages of using observed damage data to produce vulnerability functions; these shortcomings are mainly related to errors in the compilation of damage survey forms, the incompleteness of the surveys, and the difficulties in predicting the ground motion to which the buildings were subjected (see, e.g., [2]).

Analytical vulnerability methods are becoming ever more popular, but one of the main criticisms assigned to these methods relates to a lack of validation or verification of the damage predictions. Comparisons of analytical damage predictions with observed damage data is one way in which these criticisms can be addressed; however, there are a large number of difficulties with such comparisons. Even with access to detailed exposure and damage data, the main difficulty in comparing the predictions from an analytical method with the actual damage data resides in the uncertainty in the prediction of the ground motion (see, e.g., $[3,4])$. Without recordings of the ground motion at the locations of the damaged buildings, it is hard to know whether the errors in the predictions are due to an incorrect estimation of the vulnerability or of the ground motion. Whilst studies will continue to be carried out with the aim of verifying or validating analytical vulnerability assessment methodologies, the authors of this paper have decided to focus their efforts on checking the conceptual aspects of two mechanics-based methods which they have proposed (DBELA and SP-BELA). In fact, one of the major advantages of analytical vulnerability assessment methods is that even without the possibility to check the methods with field data, the patterns in the behaviour of different building classes can be physically explained.

The premise for the verification of the structural capacity defined in the two simplified vulnerability assessment methods considered herein is that the nonlinear response 
of a reinforced concrete structure can be obtained from a nonlinear static analysis of the structure. This requires the variability in the dynamic response of the building to be ignored, but it is noted that this source of variability could nevertheless be subsequently included in the methods by carrying out a number of nonlinear dynamic analyses. In this paper, finite element nonlinear static analyses of gravity-load designed and seismically-designed 4 storey reinforced concrete buildings will be compared with the lateral strength and initial stiffness predicted from two simplified vulnerability methods, DBELA and SP-BELA. The aim of this comparison is to verify and compare the definition of the structural capacity within these two methods for individual structures. The vulnerability predictions of these two methods in terms of vulnerability curves, describing the probability of exceeding a damage state given a level of severity of the ground motion, will also be compared and the differences between the two methods will be discussed.

\section{Mechanics-Based Methodologies}

In the following sections, the two vulnerability methodologies considered herein are briefly described. More details on the derivation and implementation of the methods are given in Crowley et al. [5] for the displacement-based earthquake loss assessment (DBELA) method and Borzi et al. [6] for the simplified pushover-based earthquake loss assessment (SPBELA) method.

2.1. DBELA. The displacement-based earthquake loss assessment (DBELA) method is based on a procedure proposed by Calvi [7] which utilises the principles of the direct displacement-based design method (e.g., [8]). In DBELA, as in the method proposed by Calvi [7], the period of vibration of a building is defined from an empirical periodheight relationship. The multidegree-of-freedom (MDOF) building is modelled as a single DOF system and the displacement capacity of the SDOF system is compared with the displacement demand from a displacement response spectrum, as described further in the following.

For reinforced concrete frames, the elastic period of vibration is related to the building height through a relationship that has been derived from the periods of vibration calculated analytically for a number of existing European RC buildings $[9,10]$. For bare reinforced concrete frames, the following equation has been derived:

$$
T_{\text {LSy }}=0.1 H \text {, }
$$

where $T_{\mathrm{LSy}}$ is the period of vibration at yield and $H$ is the height of the building, in metres. Buildings designed using design codes based on modern seismic design philosophy were also briefly studied by Crowley [11], and it was found that the period of vibration of these frames was much lower than that of the older pre-1980 buildings. The yield period of vibration for a limited number of frames from 4 to 12 storeys designed with the modern codes was found to be represented by the following formula:

$$
T_{\mathrm{LSy}}=0.48 H^{0.3} \text {. }
$$

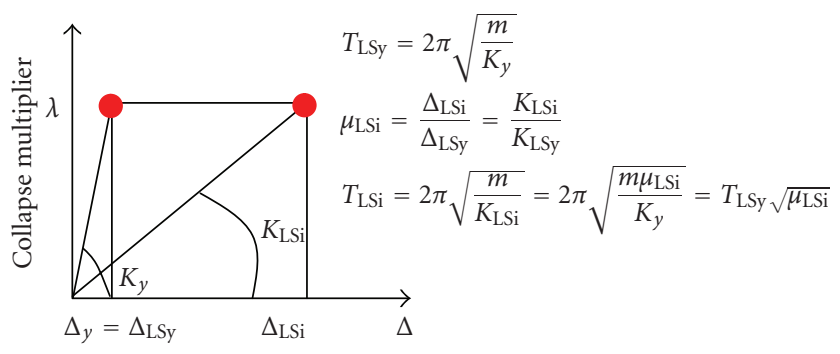

FIGURE 1: Capacity curve illustrating elastic perfectly-plastic structural behaviour and the displacement capacity at different limit states $\left(\Delta_{\mathrm{LSi}}\right)$, the collapse multiplier $(\lambda)$, and secant stiffness $\left(K_{i}\right)$.

In DBELA, elastic perfectly-plastic behaviour is assumed and, therefore, the relationship between the elastic period of vibration and the period corresponding to a limit state $i\left(T_{\mathrm{LSi}}\right)$ is given by the following relationship, which is also illustrated in Figure 1:

$$
T_{\mathrm{LSi}}=T_{\mathrm{LSy}} \sqrt{\mu_{\mathrm{LSi}}} .
$$

where $\mu_{\mathrm{LSi}}$ is the ductility at the limit state under consideration. The collapse multiplier shown in Figure 1 is the base shear capacity of the building divided by its seismic weight (which is $100 \%$ dead load plus $30 \%$ of the live load).

The displacement capacity of the building is related to different damage states which are identifiable through limit states (see Figure 1). Three limit state conditions have currently been taken into account: light damage, significant damage, and collapse. The light damage limit condition refers to the situation where the building can be used after the earthquake without the need for repair and/or strengthening. If a building deforms beyond the significant damage limit state, it cannot be used after the earthquake without strengthening. Furthermore, at this level of damage it might not be economically advantageous to repair the building. If the collapse limit condition is achieved, the building becomes unsafe for its occupants as it is no longer capable of sustaining any further lateral force nor the gravity loads for which it has been designed.

The limit state conditions are related to the rotation requirements imposed on the plastic hinges within the building that lead to the formation of a mechanism. Figure 2 shows the possible response mechanisms of a reinforced concrete frame: a beam-sway mechanism is caused by plastic hinges forming in all the beams above the first floor and in all of the columns at the base of the building whilst the column-sway mechanism forms when plastic hinges form at both ends of the columns in the ground floor. Based on the shape of the displaced profile, the displacement capacity of the equivalent SDOF system can be calculated using the elastic displacement and the post-elastic displacement at the height of the SDOF system, as described below. In DBELA, without detailed information on the strength of the building, the collapse failure mechanism is an assumption that has to be made a priori. For seismically designed buildings, a beam sway collapse mechanism is considered with the activation 
of the mechanism at the foundation level (see Figure 2(a)). For nonseismically designed RC buildings, a column-sway collapse mechanism is generally assumed with a soft storey at the first floor (see Figure 2(b)). Future developments of the method will consider the possibility of attaining a mechanism at any storey within the building.

The equations used to calculate the displacement capacity in DBELA are described in detail in Crowley et al. [5]. The yield displacement capacity, $\Delta_{\mathrm{LSy}}$, is calculated by the yield chord rotation of a single degree of freedom system $\left(\Theta_{y}\right)$ multiplied by the effective height of the building $\left(\kappa_{1} H_{T}\right)$, as shown in (4). The yield rotation for the beam-sway frames is shown in (5) whilst that of the column-sway frames is given in (6), where $l_{b}$ is the length of the beam, $h_{b}$ is the depth of the beam, $h_{s}$ is the height of the storey, and $h_{c}$ is the depth of the column:

$$
\begin{gathered}
\Delta_{\mathrm{LSy}}=\kappa_{1} H_{T} \Theta_{\mathrm{y}}, \\
\Theta_{y}=0.5 \varepsilon_{y} \frac{l_{b}}{h_{b}}, \\
\Theta_{y}=0.43 \varepsilon_{y} \frac{h_{s}}{h_{c}} .
\end{gathered}
$$

The post-yield displacement capacity is calculated using (7) and (8) for beam and column-sway frames, respectively, where $H_{k}$ is the equivalent height of the part of the building above the activation of the global collapse failure mechanism. The limit state chord rotation $\left(\Theta_{\mathrm{LSi}}\right)$ is given by (9), where $\phi_{\mathrm{LSi}}$ and $\phi_{y}$ represent the limit state and yield curvatures, respectively, and $L_{\mathrm{pl}}$ is the plastic hinge length:

$$
\begin{gathered}
\Delta_{\mathrm{LSi}}=\Delta_{\mathrm{LSy}}+\left(\Theta_{\mathrm{LSi}}-\Theta_{y}\right) H_{\mathrm{k}}, \\
\Delta_{\mathrm{LSi}}=\Delta_{\mathrm{LSy}}+\left(\Theta_{\mathrm{LSi}}-\Theta_{y}\right) h_{s}, \\
\Theta_{\mathrm{LSi}}=\Theta_{y}+\left(\phi_{\mathrm{LSi}}-\phi_{y}\right) L_{\mathrm{pl}} .
\end{gathered}
$$

The limit state and yield curvatures are proportional to the strains in the material and inversely proportional to the section depth (e.g., [12]) whilst the plastic hinge length is proportional to the section depth. Hence, it is apparent that knowledge of a number of geometrical and material properties allows the displacement capacity of reinforced concrete buildings to be estimated.

2.2. SP-BELA. The simplified pushover-based earthquake loss assessment (SP-BELA) method makes use of a simplified pushover methodology to evaluate the capacity of the building stock. Pushover curves are calculated for buildings with a given layout in plan, such as that shown in Figure 3; this is a typical plan for Southern European and Italian buildings (see, e.g., [13-15]). The prototype structure defined for nonseismically designed buildings has the frames oriented in one direction only (the $x$ direction), and in the orthogonal direction the frame effect is guaranteed by an effective width of the floor slab. For seismically designed frames, the frame action is ensured in both orthogonal directions of the building. A simulated design procedure is first used to design each prototype building and assign beam and

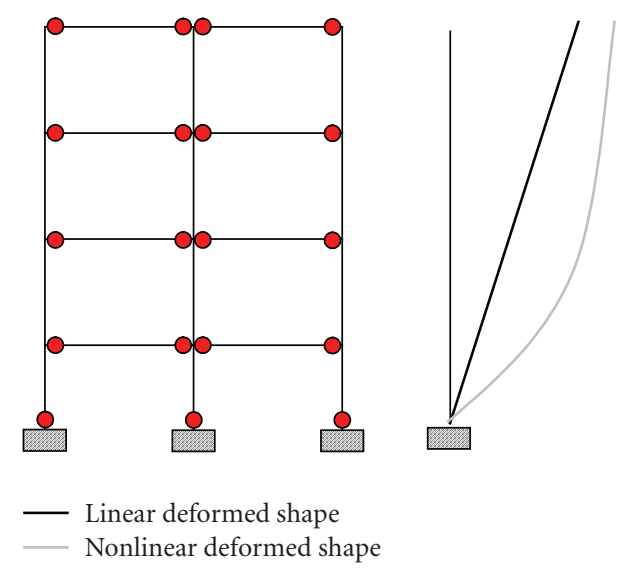

(a)

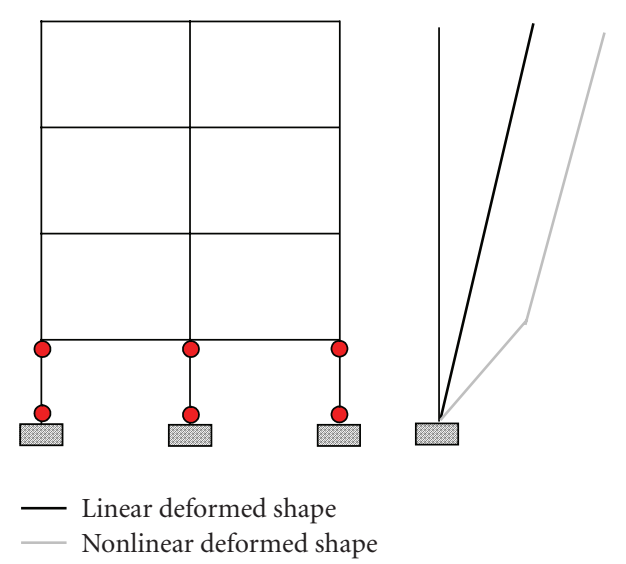

(b)

FIGURE 2: Response mechanisms for a frame and the associated deformed shapes (a) beam-sway mechanism, (b) column-sway mechanism.

column dimensions and reinforcement details. In SP-BELA, to account for seismically designed buildings, the method of equivalent static lateral distribution of forces has been adopted during the simulated design procedure by assuming a lateral load coefficient, $c$, corresponding to $5 \%, 7.5 \%$, $10 \%$, and $12.5 \%$ of the seismic weight (which is the dead weight plus $30 \%$ of the live load). These values of lateral load coefficient have been chosen considering the evolution of seismic design practice in Italy $[16,17]$. In the 1930s in Italy, the lateral load coefficient was defined as $10 \%$ of the weight in the highest seismic zone and $7 \%$ in the second seismic zone. A third seismic zone was introduced in the 1980 s with a lateral load coefficient of $4 \%$. Considering these values as a basis, and the possibility that importance factors would increase these values of $c$ for certain structures, the aforementioned range of lateral load coefficients was decided upon for the current study. In the design procedure, capacity design is not currently integrated, since seismic design codes 


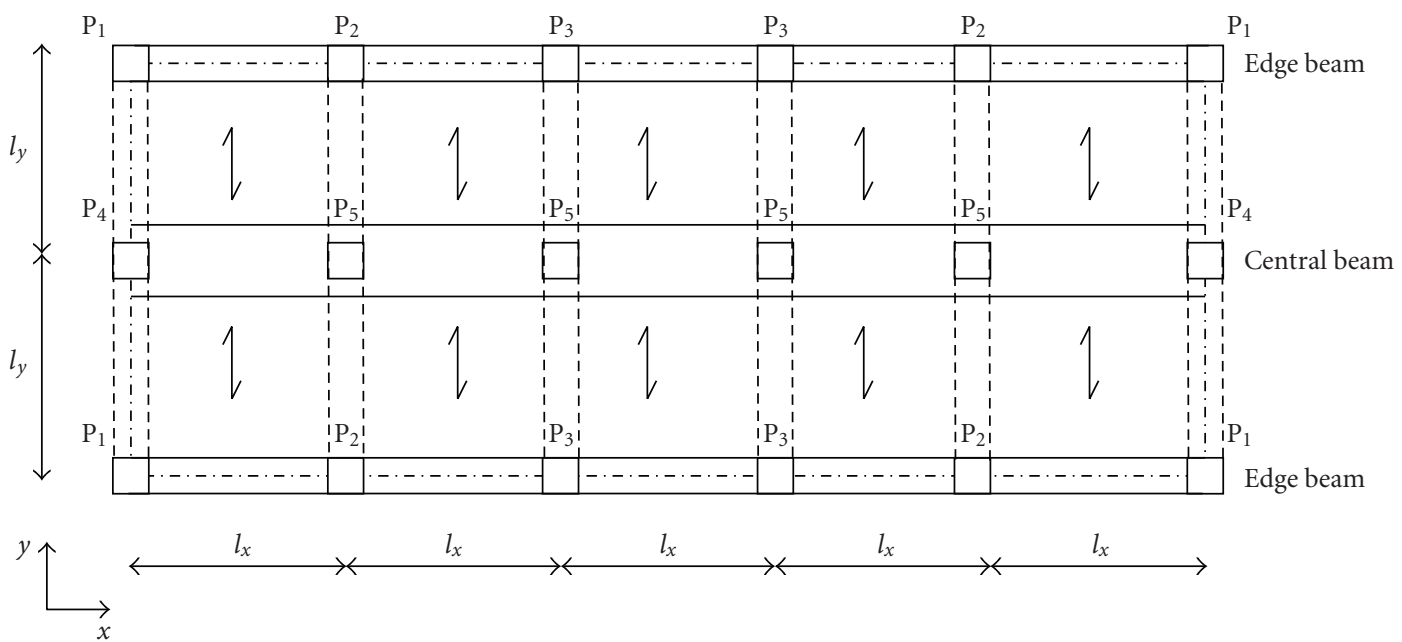

FIGURE 3: Plan view of the RC frame building assumed as representative of the building structural type for seismically designed buildings in Mediterranean countries.

in the Mediterranean area have only recently begun to take a hierarchy of resistance into account.

Once the prototype building has been designed, a simplified pushover curve is produced considering simple principles of mechanics in order to define the collapse multiplier $(\lambda)$ (which represents the base shear capacity divided by the seismic weight). This multiplier, together with the yield displacement capacity $\left(\Delta_{y}\right)$, is used to calculate the yield stiffness and subsequently the elastic period of vibration $\left(T_{\text {LSy }}\right)$ based on the elastoplastic behaviour shown previously in Figure 1:

$$
T_{\text {LSy }}=2 \pi \sqrt{\frac{m}{K_{y}}}=2 \pi \sqrt{\frac{\Delta_{y} g}{\lambda}} .
$$

The post-yield period of vibration is calculated in the same way as described previously for DBELA. The limit state definition and displacement-based framework used in SPBELA is also based on (4), (7), and (8); however the yield and ultimate chord rotations are taken from the proposals by Panagiotakos \& Fardis (2001) [18]. The chord rotation corresponding to yielding $\Theta_{y}$ is thus given by

$$
\Theta_{y}=\phi_{y} \frac{L_{V}}{3}+0.0013\left(1+1,5 \frac{h}{L_{V}}\right)+0.13 \phi_{y} \frac{d_{b} f_{y}}{\sqrt{f_{c}}}
$$

where $\phi_{y}$ is the yield curvature of the columns, $h$ is the section height, $d_{b}$ is the longitudinal bar diameter, $f_{y}$ and $f_{c}$ are the resistance of steel and concrete in $\mathrm{MPa}$, respectively, and $L_{V}$ is the shear span of the columns (equal to the ratio between bending moment and shear). A double bending distribution is commonly assumed for columns, and hence $L_{V}$ is taken as half of the interstorey height. The ultimate limit state chord rotation is calculated using the following formula:

$$
\Theta_{\mathrm{LSi}}=\frac{1}{\gamma_{\mathrm{el}}}\left(\Theta_{y}+\left(\phi_{\mathrm{LSi}}-\phi_{y}\right) L_{\mathrm{pl}}\left(1-\frac{0.5 L_{\mathrm{pl}}}{L_{V}}\right)\right),
$$

where $\gamma_{\mathrm{el}}$ is 1.5 for the primary structural elements and 1 for all others, $\phi_{u}$ is the ultimate curvature, and $L_{\mathrm{pl}}$ is the plastic hinge length. According to the new Italian regulations OPCM N $\mathrm{N}^{\circ} 3274$ [19], the plastic hinge length can be calculated as

$$
L_{\mathrm{pl}}=0,1 L_{V}+0,17 h+0,24 \frac{d_{b} f_{y}}{\sqrt{f_{c}}},
$$

whilst the ultimate curvature is assumed to be

$$
\phi_{u}=\frac{\varepsilon_{\mathrm{cu}}+\varepsilon_{\mathrm{su}}}{h},
$$

where $\varepsilon_{\mathrm{cu}}$ and $\varepsilon_{\mathrm{su}}$ are the ultimate concrete and steel strains, respectively.

In SP-BELA no a priori assumptions are necessary to define the collapse mechanism, as this is determined within the procedure by checking which elements of the frame will fail first considering the relative strength between the beams and the columns; thus, the mechanism can be found to form on any floor of the building. The definition of the failure mechanism in SP-BELA is discussed further in Section 3.2.

\section{Verification Through Finite Elements Analysis}

3.1. Case-Studies Considered and Modelling. The prototype structure presented in Figure 3 has been designed with 4 storeys according to the 1992 Italian reinforced concrete design code [20], first considering gravity loads alone and then assuming lateral loads of $5 \%, 7.5 \%, 10 \%$, and $12.5 \%$ of the seismic weight. The characteristic concrete compressive strength has been taken as $30 \mathrm{MPa}$ and the characteristic yield strength of the steel has been taken as $440 \mathrm{MPa}$. The main characteristics of the central frame in the $x$ direction are presented for each design case in Tables 1 and 2 . 
TABLE 1: Geometrical properties of the central frame of the prototype building in Figure 3 designed to different proportions of lateral load (c).

\begin{tabular}{|c|c|c|c|c|c|}
\hline \multirow{2}{*}{ Section } & \multicolumn{5}{|c|}{ Depth*/width (mm) } \\
\hline & $c=0 \%$ & $c=5 \%$ & $c=7.5 \%$ & $c=10 \%$ & $c=12.5 \%$ \\
\hline Central beam & $320 / 1300$ & $370 / 1500$ & $370 / 1800$ & $420 / 1600$ & $420 / 1900$ \\
\hline \multicolumn{6}{|l|}{ Col P4 } \\
\hline 1st Fl & $300 / 400$ & \multirow[b]{2}{*}{$300 / 300$} & \multirow[b]{2}{*}{$300 / 400$} & \multirow[b]{2}{*}{$300 / 400$} & \multirow[b]{2}{*}{$300 / 600$} \\
\hline $\begin{array}{l}\text { 2nd Fl } \\
\text { 3rd Fl } \\
\text { 4th Fl }\end{array}$ & $300 / 300$ & & & & \\
\hline \multicolumn{6}{|l|}{ Col P5 } \\
\hline 1st Fl & $700 / 300$ & \multirow{4}{*}{$600 / 300$} & \multirow{4}{*}{$900 / 300$} & \multirow{4}{*}{$800 / 400$} & \multirow{4}{*}{$800 / 400$} \\
\hline 2nd Fl & $600 / 300$ & & & & \\
\hline 3rd Fl & $400 / 300$ & & & & \\
\hline 4th Fl & $300 / 300$ & & & & \\
\hline
\end{tabular}

TABLE 2: Reinforcing steel in the design of the central frame of the prototype building in Figure 3 designed to different proportions of lateral load $(c)$.

\begin{tabular}{|c|c|c|c|c|c|}
\hline \multirow{2}{*}{ Section } & \multicolumn{5}{|c|}{$\%$ area of tensile reinforcing steel } \\
\hline & $c=0 \%$ & $c=5 \%$ & $c=7.5 \%$ & $c=10 \%$ & $c=12.5 \%$ \\
\hline Central beam & $0.30 / 0.68^{* *}$ & $0.40 / 0.74$ & $0.38 / 0.75$ & $0.42 / 0.79$ & $0.39 / 0.75$ \\
\hline \multicolumn{6}{|l|}{ Col P4 } \\
\hline 1st Fl & 0.67 & \multirow{4}{*}{1.4} & \multirow{4}{*}{1.2} & \multirow{4}{*}{2.1} & \multirow{4}{*}{1.5} \\
\hline 2nd Fl & 0.89 & & & & \\
\hline 3rd Fl & 0.45 & & & & \\
\hline 4th Fl & 0.45 & & & & \\
\hline \multicolumn{6}{|l|}{ Col P5 } \\
\hline 1 st Fl & 1.20 & \multirow{4}{*}{1.5} & \multirow{4}{*}{1.1} & \multirow{4}{*}{0.9} & \multirow{4}{*}{0.9} \\
\hline 2nd Fl & 0.81 & & & & \\
\hline 3rd Fl & 0.67 & & & & \\
\hline 4th Fl & 0.45 & & & & \\
\hline
\end{tabular}

Nonlinear finite element models of the designed structures have been modelled using the program SeismoStruct [21]. This program is capable of predicting the large displacement behaviour and the collapse load of framed structures under static or dynamic loading, duly accounting for geometric nonlinearities and material inelasticity. Its accuracy in predicting the seismic response of reinforced concrete structures has been demonstrated through comparisons with experimental results derived from pseudodynamic tests carried out on large-scale models (e.g., [22, 23]).

A static pushover analysis of each building has been carried out in the $x$ direction of the building as this is the direction of the building where the frame action is guaranteed for both nonseismically and seismically designed buildings. For the pushover analysis, the mean compressive strength of the concrete has been assumed to be $37.35 \mathrm{MPa}$ whilst the mean yield strength of the steel has been taken as $473 \mathrm{MPa}$.
3.2. Failure Mechanism. One first comparison that can be made regards the failure mechanism obtained with both methods. In SP-BELA, the mechanism is calculated by considering the following criteria.

(i) If there is a shear failure mechanism detected in at least one column, the capacity curve will be interrupted at the lateral force that produces this failure. This choice is consistent with the fact that the shear failure mechanism is brittle and does not have significant associated dissipative capacity. Therefore, the structure cannot enter the nonlinear range.

(ii) If all the columns within a certain storey fail in bending, than a column-sway collapse mechanism will be activated.

(iii) If after the development of plastic hinges in all beams, plastic hinges form in all columns at a certain level, a beam-sway collapse mechanism will be activated. 
TABLE 3: Sway potential index calculated using the formula in (15) for the 4-storey building from Figure 3 designed to different proportions of lateral load $(c)$.

\begin{tabular}{lccccc}
\hline Floor & $c=0 \%$ & $c=5 \%$ & $c=7.5 \%$ & $c=10 \%$ & $c=12.5 \%$ \\
\hline 1st & 0.5 & 0.6 & 0.5 & 0.4 & 0.4 \\
2nd & 1.0 & 0.6 & 0.5 & 0.4 & 0.4 \\
3rd* & 2.6 & 0.6 & 0.5 & 0.4 & 0.4 \\
\hline
\end{tabular}

* The storey mechanism for the fourth floor is not calculated as plastic hinges are likely to form in the top of the columns at the roof, even for a global mechanism.

There could be a situation in which at the storey where the mechanism is activated, some of the columns are stronger than the beams, or vice versa. Therefore, it cannot be clearly identified whether a beam or a column-sway mechanism will be activated. The analyses undertaken to validate the SPBELA procedure have shown that in such cases the collapse mechanism can be assumed as a mixed mechanism defined using the average displacement capacities of the column and beam-sway mechanisms.

If the reinforcing steel is known in the building then a sway potential index can be estimated in DBELA in order to define the mechanism, using the following simplified formula based on the proposal by Priestley et al. [24]:

$$
\begin{aligned}
S_{I} & =\frac{\sum\left(M_{\mathrm{bl}}+M_{\mathrm{br}}\right)}{\sum\left(M_{\mathrm{ca}}+M_{\mathrm{cb}}\right)} \propto \frac{\sum\left(h_{b} A_{\mathrm{sb}} f_{y}\right)_{l}+\left(h_{b} A_{\mathrm{sb}} f_{y}\right)_{r}}{\sum\left(h_{c} A_{\mathrm{sc}} f_{y}\right)_{c}+\left(h_{c} A_{\mathrm{sc}} f_{y}\right)_{b}} \\
& =\frac{\sum\left(h_{b} A_{\mathrm{sb}}\right)_{l}+\left(h_{b} A_{\mathrm{sb}}\right)_{r}}{\sum\left(h_{c} A_{\mathrm{sc}}\right)_{a}+\left(h_{c} A_{\mathrm{sc}}\right)_{b}},
\end{aligned}
$$

where $M_{\mathrm{bl}}$ and $M_{\mathrm{br}}$ are the flexural strengths at either side of the joint (where $l$ is left and $r$ is right), and $M_{\mathrm{ca}}$ and $M_{\mathrm{cb}}$ are the flexural column strengths (a) above and (b) below the joint, all of which are summed for all joints of a given floor. This formula can be simplified using just the area of tensile reinforcing steel $A_{\mathrm{sb}}$ in each beam left and right of the joint, the area of tensile reinforcing steel in each column, $A_{\mathrm{sc}}$ above and below the joint, the beam section dimensions, $h_{b}$, and the column section dimensions, $h_{c}$, either side of the joint and $f_{y}$ which is the yield strength of the steel, as shown in (15). If the sway index is higher than 1 , a columnsway mechanism is assumed to form (see Figure 2(b)), below 0.85 a beam sway mechanism (see Figure 2(a)) will form whilst between 0.85 and 1 it is conservative to assume a column-sway mechanism. It is clear from this formula that when the reinforcement is unknown, in DBELA the collapse mechanism needs to be selected a priori assuming that seismically and nonseismically designed buildings are more prone to a beam- and column-sway mechanism, respectively.

The calculated sway potential indices from DBELA for the 5 different designs of the 4 storey building are reported in Table 3. These calculations show that a column-sway mechanism in the third floor of the nonseismically designed building is predicted whilst all seismically designed buildings demonstrate a beam-sway or global mechanism. SP-BELA also predicts a column-sway at the third floor of the

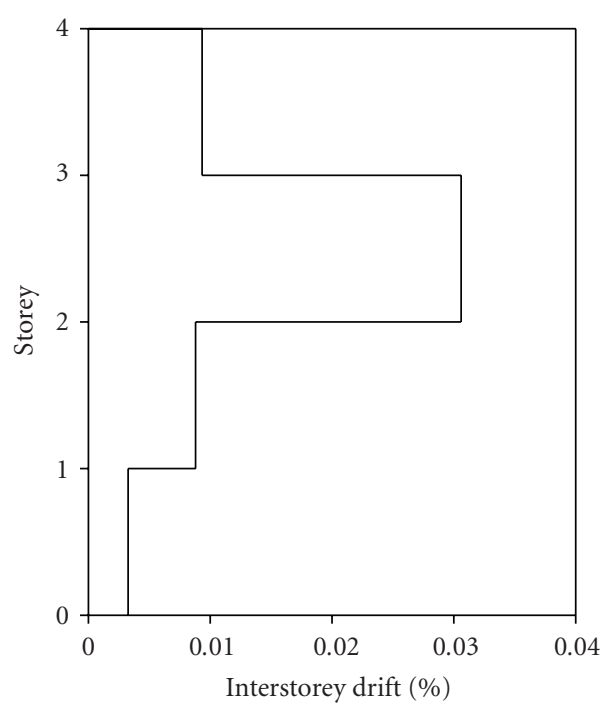

(a)

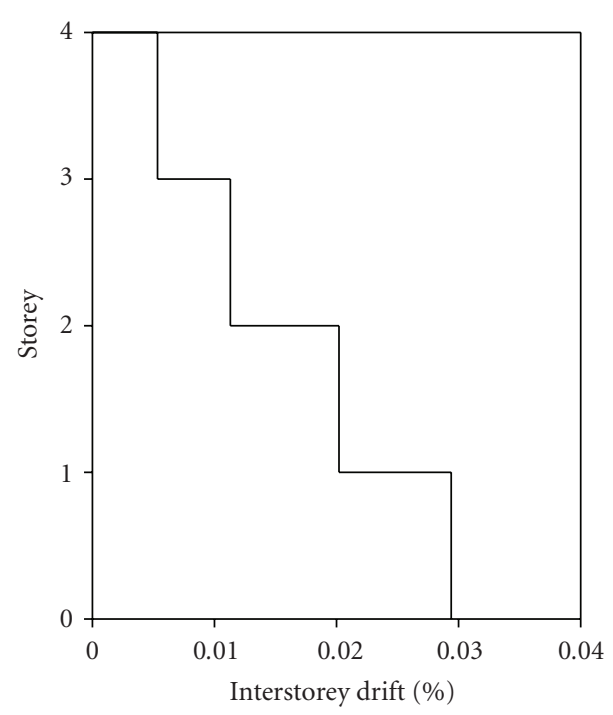

(b)

Figure 4: Post-yield interstorey drift profiles in $x$ direction of the building in Figure 3 (a) nonseismically designed (b) $c=5 \%$.

building designed to gravity loads (i.e., $c=0 \%$ ) and global mechanisms for all other buildings.

The mechanisms observed by plotting the deformed shapes from the finite elements analyses were in full agreement with the predictions by both DBELA and SPBELA, as can be seen from the post-yield interstorey drift profiles for the nonseismically designed and the seismicallydesigned $(c=5 \%)$ design cases in Figure 4 . The third storey sway mechanism is clearly present in the nonseismically designed frame whilst the seismically designed building has a global mechanism.

3.3. Yield Displacement Capacity, Collapse Multiplier, and Initial Stiffness. The yield displacement capacity of the 


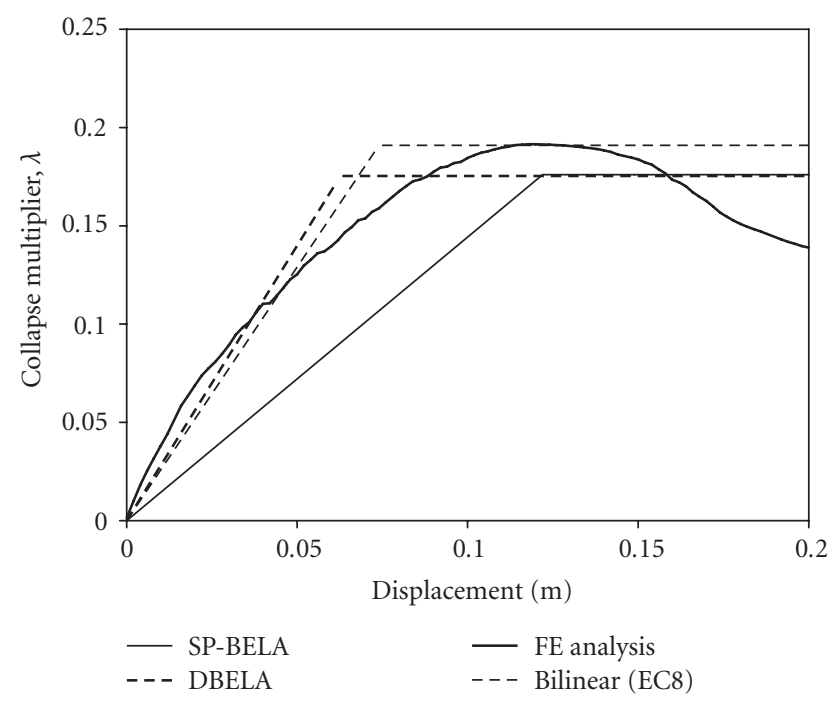

(a)

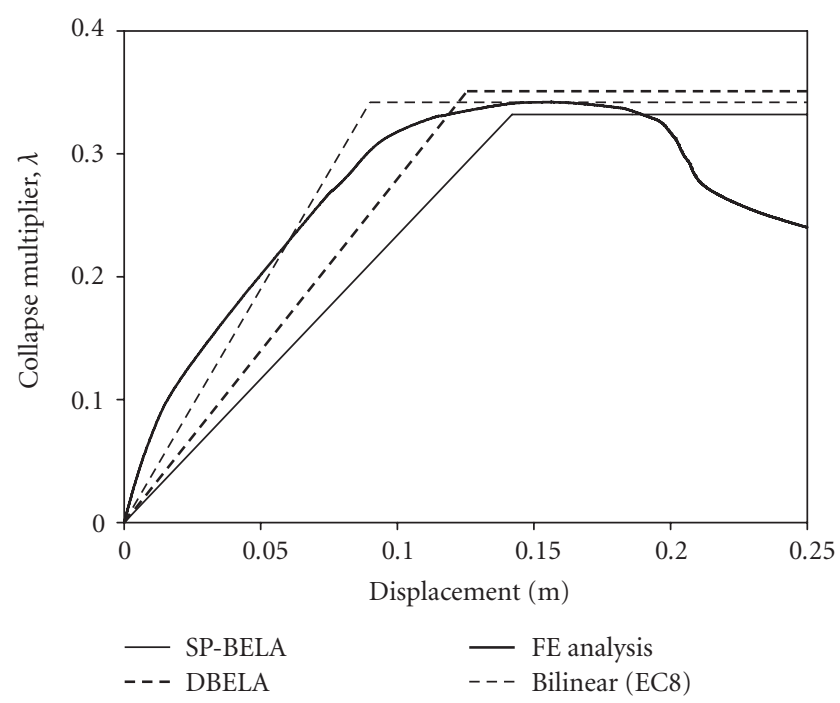

(b)

Figure 5: Comparison of pushover analyses in $x$ direction of the building in Figure 3 (a) nonseismically designed (b) $c=5 \%$.

building in the $x$ direction has been calculated in both methodologies using the section properties, the yield strain of the steel, and the appropriate yield rotation equations. The value of the collapse multiplier is explicitly calculated in SP-BELA based on the strength of the structural members. On the other hand, in DBELA the collapse multiplier $(\lambda)$ has been calculated using the results of the displacement capacity $\left(\Delta_{y}\right)$ and the period of vibration at yield $\left(T_{y}\right)$ using the following formula, which is simply a rearrangement of (10):

$$
\lambda=\frac{4 \pi^{2} \Delta_{y}}{g T^{2}}=\frac{4 \pi^{2} \Delta_{y}}{g(0.1 H)^{2}} .
$$

The pushover plots of collapse multiplier (which is equal to the base shear force divided by the seismic weight) versus displacement at the effective height of the building for the nonseismically designed and the 5\% laterally loaded building are plotted in Figures 5(a) and 5(b), respectively. These figures show the nonlinear pushover plot from the finite elements model compared with the simplified bilinear pushover plots of SP-BELA and DBELA. A bilinear pushover curve based on the method described in Annex B of Eurocode 8 [25] has also been added to the plots to ease comparison between the results of the simplified methods and the finite element analyses. The comparison with the finite elements pushover analysis is seen to be acceptable for both DBELA and SP-BELA in terms of the collapse multiplier. However, it is apparent that SP-BELA underestimates and DBELA slightly overestimates the stiffness of the nonseismically designed building, which responds with a column-sway mechanism. In SP-BELA the yield stiffness is obtained from the calculated base shear capacity and the yield displacement. The yield displacement is based on the yield rotation in (11) which includes additional shear and joint deformations which are not accounted for in the finite elements package, thus explaining the lower stiffness prediction with SP-BELA. Both SP-BELA and DBELA underestimate the stiffness of the seismically designed building (see Figure 5(b)) which responds with a beam-sway mechanism; again this is probably due to the additional shear and joint deformations explicitly accounted for in the beam-sway rotation in DBELA (see (5) ) and the equivalent equation used in SP-BELA (see (11)). It is noted that the equation for beam-sway rotation used in DBELA (see (5)) has been specifically calibrated to account for shear and joint deformations, whereas the associated increase assumed in the column-sway rotation equation (see (6)) has not yet been verified (see [26]).

Figure 6(a) presents the comparison for the building designed to a lateral load of $7.5 \%$ of the seismic weight. SP-BELA is seen to correctly predict the collapse multiplier of this frame, whilst DBELA greatly underpredicts the strength, though the displacement capacity is similar for both methods. The reason for this difference is due to the imposed period of vibration and thus initial stiffness used in DBELA. This formula, presented previously in (1), has been derived using the regression analysis of the period of vibration of nonseismically or weakly seismically designed frames. Under conventional force-based design, the consideration of lateral loads in the design of a frame or building will undoubtedly increase the lateral stiffness of the building through the need to use larger section dimensions for the columns. This can be seen by studying the section dimensions of the frame shown in Table 1. A lower period of vibration should thus be used for seismically designed buildings. A modified period-height relationship $(T=$ $0.085 \cdot H$ ) which is found to give good results for the building designed to the $7.5 \%$ lateral force is shown in Figure 6(b), whereas even lower periods of vibration are required for the buildings designed to lateral forces of $10 \%$ and $12.5 \%$ of the seismic weight, as shown in Figures $7(\mathrm{a})$ and $7(\mathrm{~b})$, respectively. SP-BELA is seen in these figures to consistently match the collapse multiplier for all seismic designs as the strength of the building is explicitly calculated as part of this methodology. 


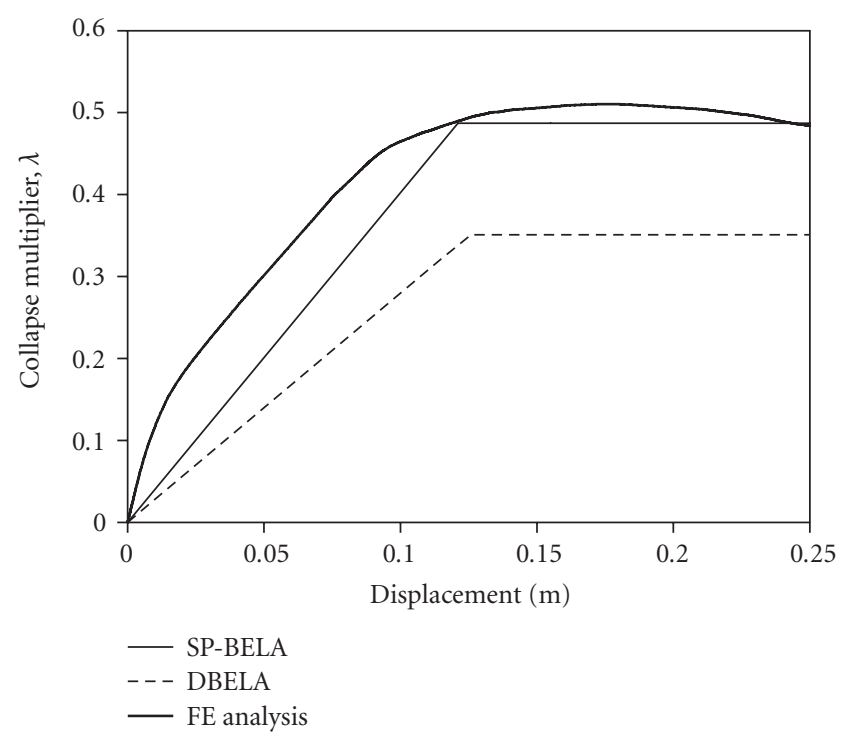

(a)

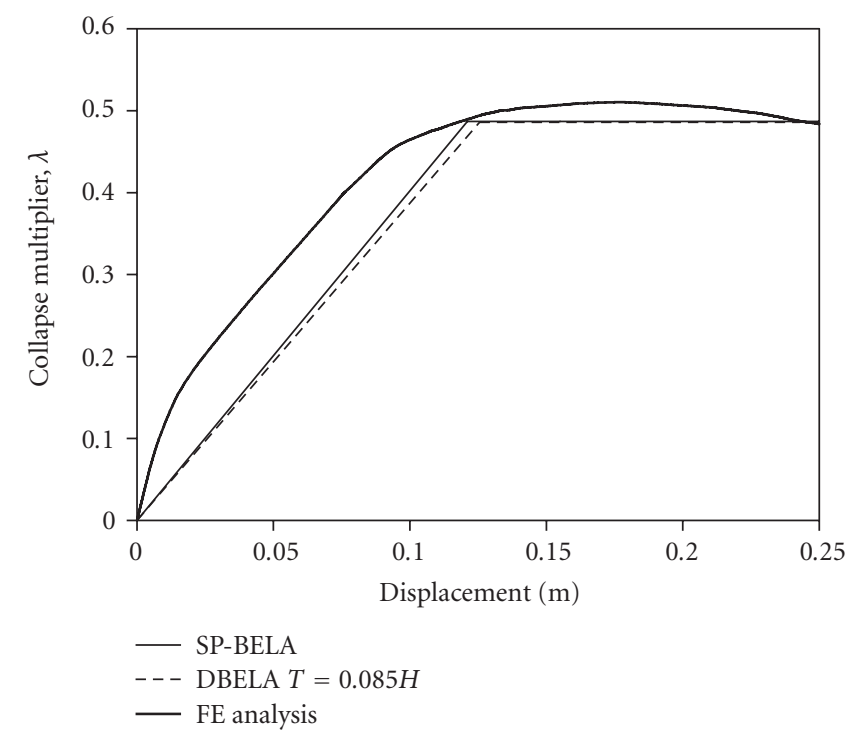

(b)

FIGURE 6: Comparison of pushover analyses for seismically designed building, $c=7.5 \%$, (a) original period-height relationship in DBELA (b) modified period-height relationship in DBELA.

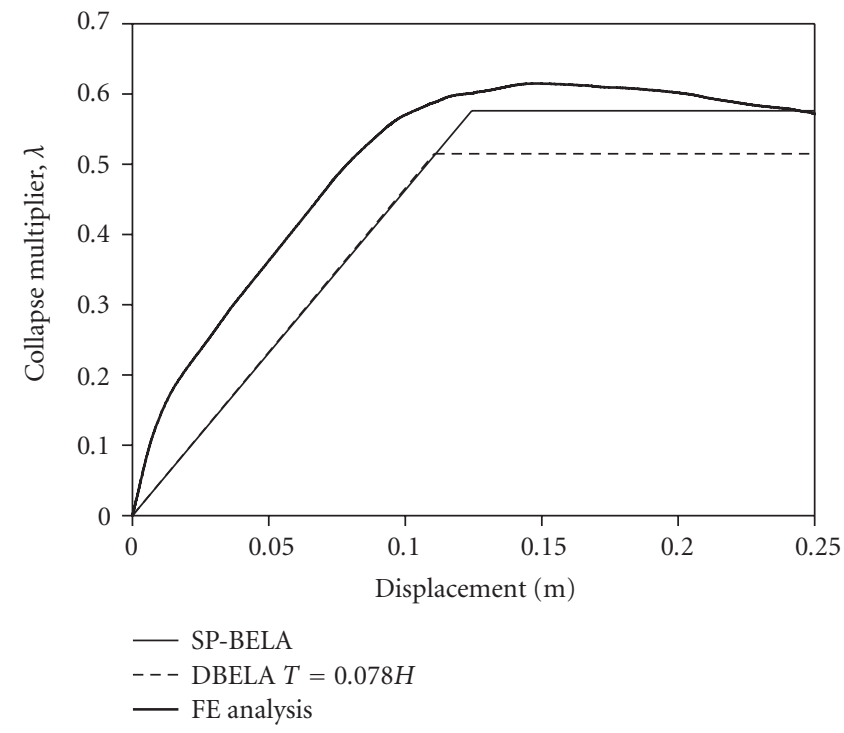

(a)

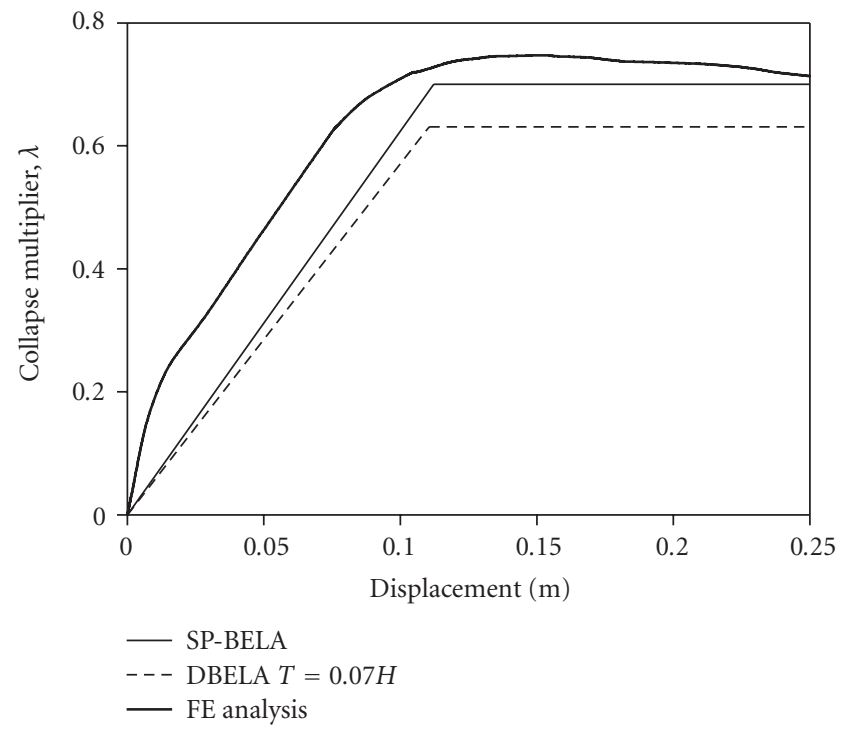

(b)

Figure 7: Comparison of pushover analyses for seismically designed building (a) $c=10 \%$ (b) $c=12.5 \%$.

It appears from the analyses presented herein that the SP-BELA methodology defines well the single-degree-offreedom structural characteristics of individual buildings, whilst further calibration of the period-height relationship used in the DBELA methodology would be required for the Southern European/Italian building stock in order to match the different levels of seismic design.

\section{Pushover Analyses of Urban Populations}

The use of DBELA and SP-BELA in the vulnerability assessment of urban areas requires many buildings with varying characteristics to be considered. In SP-BELA, this simply translates to the variation of input parameters such as design loads and bay lengths which are then used in the 
simulated design of hundreds of different buildings, whether they are designed to lateral loads and/or gravity loads. A simplified pushover is then carried out for each designed building to ascertain the lateral strength and displacement capacity based on a random definition of the material properties. DBELA requires input parameters based on just the geometrical properties and the material properties, whilst no information on the loads is needed. As the sections in the building are not designed in DBELA, additional statistics on the variation of each structural property are necessary and assumptions on the proportion of buildings with each response mechanism need to be made a priori. In order to study the influence of the differences in the way urban populations are generated in the two methods, a comparison is carried out in the next section in terms of the mean and variance of the SDOF characteristics, where the only prior information of the building stock is based on collected statistics.

4.1. Random Variables to Describe Uncertainty in Building Characteristics. The two mechanics-based vulnerability assessment methodologies treated herein use the generation of a random population of buildings to model the variation of the structural characteristics of a given building class within an urban environment. Once a random population has been derived, in DBELA the period of vibration and limit state capacity of each building are directly calculated. In SPBELA, the design of each random building is carried out (to gravity load or lateral load design), and the simplified pushover curve is generated to obtain the period of vibration, and then the limit state displacement capacities are calculated. Further details on the random variables used in each method are provided below.

SP-BELA. In order to derive vulnerability curves using this type of analytical procedure, it is necessary to randomly characterise the structural parameters and produce pushover curves for each set of randomly generated buildings. In the current application, the building characteristics that are described through random variables have been defined as follows.

(i) Geometrical dimensions: the span lengths $l_{x}$ and $l_{y}$ are in the $x$ and $y$ directions, respectively, and the interstorey height are considered as random variables. Following typical construction practice, the span length was assumed as a random variable with a uniform distribution between 4 and $6 \mathrm{~m}$. The interstorey height was, on the other hand, assumed to be deterministic and equal to $3 \mathrm{~m}$. This choice is due to the fact that the interstorey height does not generally vary significantly, and this value is usually the minimum allowed from construction standards.

(ii) Material properties: for steel, a random choice between a characteristic yielding value of $380 \mathrm{MPa}$ and $440 \mathrm{MPa}$ was performed. A randomly chosen cubic characteristic resistance of $25 \mathrm{MPa}, 30 \mathrm{MPa}$, and $35 \mathrm{MPa}$ was, on the other hand, associated to the concrete for each building of the generated dataset. The characteristic strengths (used in the simulated design) are multiplied by parameters to obtain the mean values of resistance (employed in the assessment); these parameters have a mean value of 1.1 and 1.5 for steel and concrete, respectively [28], and a coefficient of variation of $10 \%$. In both cases, a normal distribution has been assumed for these parameters; although this may lead to negative values in a very small number of cases, this only happens when a very large number of standard deviations are considered.

(iii) Design loads: a normal distribution has been adopted to represent gravity and wind loads, with the former featuring a mean value of $3 \mathrm{kN} / \mathrm{m}^{2}\left(2.5 \mathrm{kN} / \mathrm{m}^{2}\right.$ on the roof $)$ and a standard deviation of $0.5 \mathrm{kN} / \mathrm{m}^{2}$, whilst the latter has a mean value of $0.9 \mathrm{kN} / \mathrm{m}^{2}$ (with a standard deviation $0.2 \mathrm{kN} / \mathrm{m}^{2}$ ). Snow and vertical variable loads have instead been considered in a deterministic manner, with values of 1.6 and $2.0 \mathrm{kN} / \mathrm{m}^{2}$, respectively.

The dimensions and the reinforcement of the structural elements such as beams, columns, and floor slabs are not taken as random variables, since the details of structural elements are defined during the design of each randomly generated building using the chosen design regulations. The Monte Carlo generation of the random variables with a normal distribution has been undertaken using the Latin Hypercube algorithm, a technique that allows a better representation of the sample in the low probability region of the distribution (e.g., [29]).

DBELA. The same random variables described above for the geometric and material properties have been used, but additional random variables for the beam depth and column depth are required. As stated before, in SP-BELA these dimensions are assigned during the design of each random building in the dataset, whilst with DBELA the distribution of these parameters needs to be defined a priori; this can be carried out by a statistical analysis of a sample of buildings. For the comparison carried our herein, the variability of the beam depth and column depth of Italian buildings has been taken from a study by Marino [30]:

(i) mean beam depth $=0.34 \mathrm{~m}$, standard deviation $=$ $0.07 \mathrm{~m}$, lognormal distribution,

(ii) mean column depth $=0.37$, standard deviation $=$ 0.11 , lognormal distribution.

4.2. Building Characteristics of Urban Populations. An urban population of reinforced concrete buildings has been derived for both DBELA and SP-BELA using the random variables described above. The mean period of vibration in the $x$ and $y$ direction of the prototype building (see Figure 3 ) for each design type has been calculated using the SPBELA methodology for each number of storeys from 2 to 8 . The variation of the mean periods of vibration with storey number is presented in Figure 8 for the $x$ direction and in Figure 9 for the $y$ direction along with the period of vibration calculated using (1) (as used in DBELA for the older pre1980 buildings). The coefficient of variation of the period of vibration in SP-BELA is approximately 6\% in all cases whilst in DBELA it has been found to be $15 \%$. The higher coefficient 


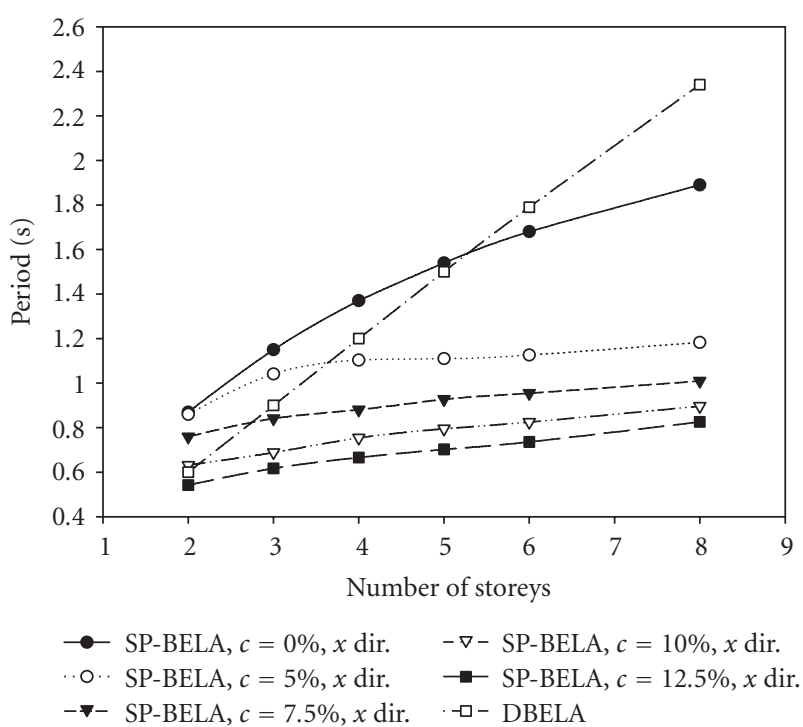

Figure 8: Mean yield period of vibration versus number of storeys for DBELA compared with each of the SP-BELA design categories in the $x$ direction.

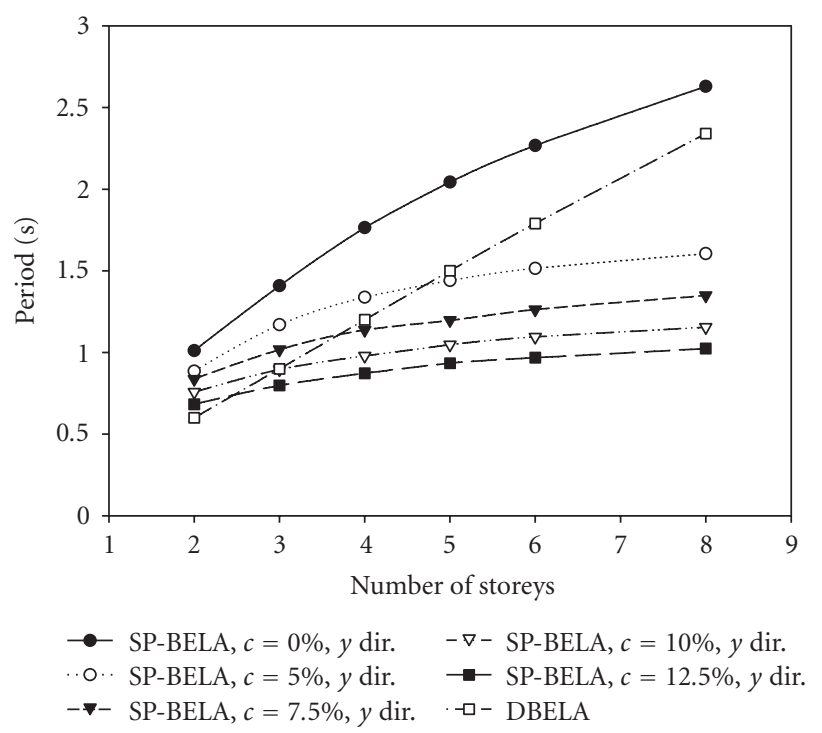

Figure 9: Mean yield period of vibration versus number of storeys for DBELA compared with each of the SP-BELA design categories in the $y$ direction.

of variation in DBELA for the period of vibration is likely to be due to the wide range of frames with different numbers of bays which were considered in the regression analysis, whilst the SP-BELA calculations have been based on a single prototype structural system (see Figure 3 ).

The comparison of the periods of vibration obtained with the two methods in the $x$ direction follows the conclusions obtained for the single building in Section 3; the period of vibration from the DBELA equation is similar to the period of vibration of the nonseismically designed

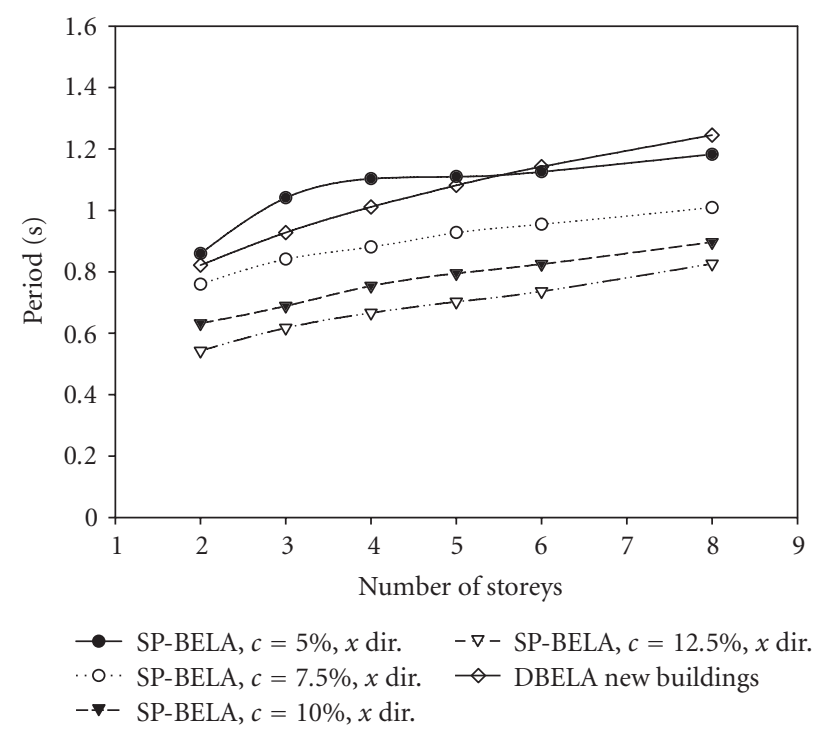

FIGURE 10: Mean yield period of vibration versus number of storeys for new buildings (DBELA) compared with the seismically designed buildings (SP-BELA) in the $x$ direction.

buildings but is much higher than the period of vibration of the seismically designed buildings. In the $y$ direction of the building, the period of the nonseismically designed buildings in SP-BELA is high due to the lack of beams in this direction of the building. On the other hand, the introduction of beams in this direction (which occurs in the seismically designed frames) leads to much higher stiffness and lower periods of vibration.

As mentioned in Section 2, the period of vibration of post-1980 frames has been studied as part of the development of DBELA, and it was found that due to the larger sections used in these frames, the period of vibration versus height formula was lower than that found for pre1980 frames. The periods predicted with (2) for different number of storeys (assuming a storey height of 3 metres) are presented in Figure 10 together with the periods of vibration found in SP-BELA for the seismically designed buildings. The close match between the seismically designed frames with $c=5 \%$ and the formula found for DBELA using newer buildings can be observed in Figure 10, whereas the frames designed to higher seismic loads in SP-BELA are seen to have even lower periods of vibration. Hence, it appears that (2) could be used for weakly seismically designed buildings in Italy. However, this formula has been based on a limited number of buildings, and further analyses are necessary to calculate the variability in the equation; for this reason, this period-height formula will not be considered in the calculations presented subsequently in this paper.

Verderame et al. [27] have derived period-height equations for the $x$ and $y$ directions of nonseismically designed Italian reinforced concrete frames with a very similar layout to that considered herein, however, with the inclusion of a staircase. The interstorey height was taken as $3 \mathrm{~m}$, the mean yield strength of the steel was assumed to be $360 \mathrm{MPa}$, and the mean compressive strength of the concrete was taken 


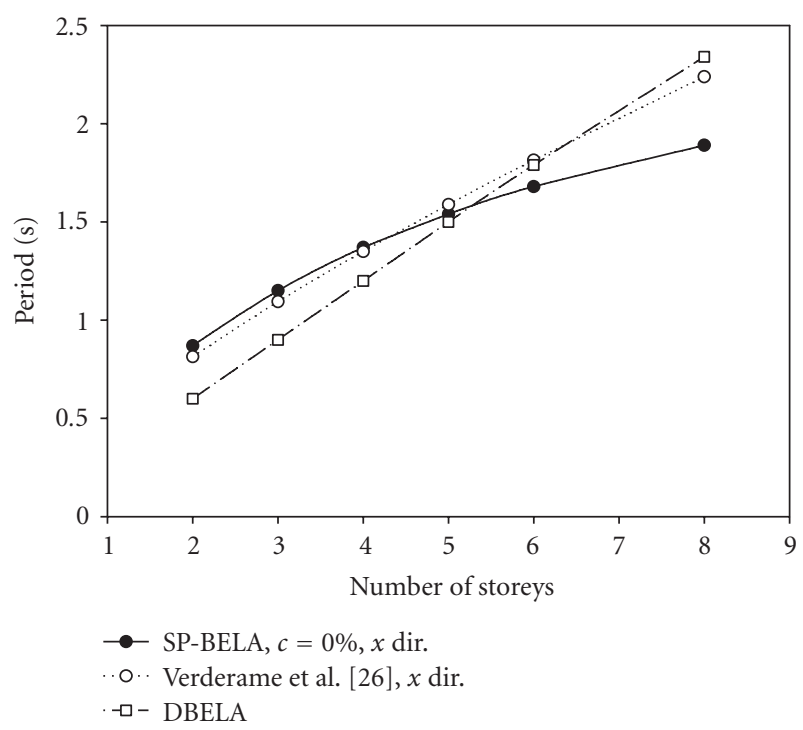

(a)

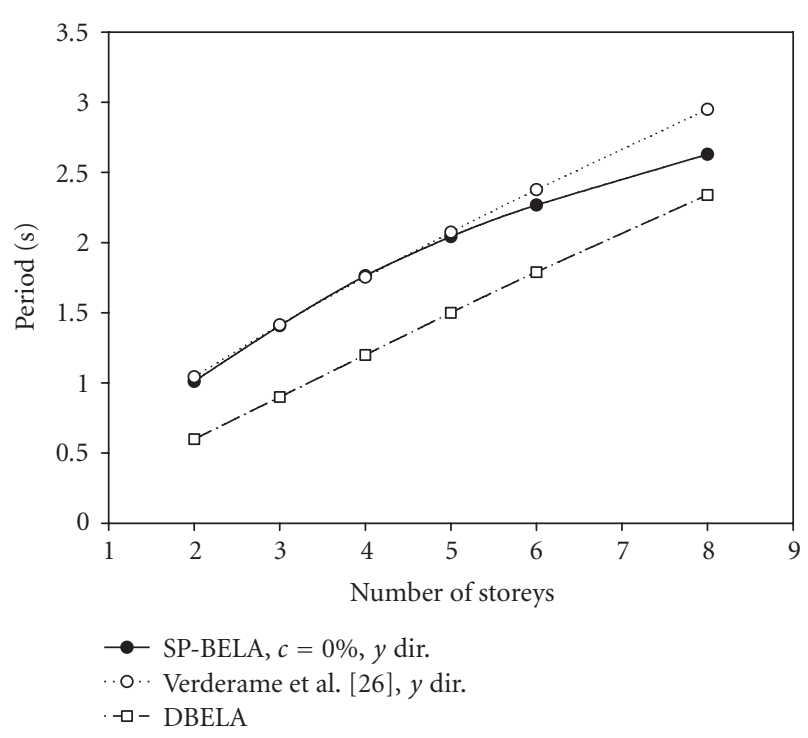

(b)

FIGURE 11: Mean yield period of vibration versus number of storeys for DBELA compared with nonseismically designed ( $c=0 \%)$ SPBELA frames and the equations proposed by Verderame et al. [27], (a) the $x$ direction and (b) the $y$ direction of the buildings.

as $25 \mathrm{MPa}$. The mean period of vibration versus number of storeys found using the equations proposed by Verderame et al. [27] in both the $x$ and $y$ directions is presented in Figure 11 along with the periods of vibration from SP-BELA and DBELA.

The variation in period with height in both the $x$ and $y$ directions is seen to match the SP-BELA results closely, whilst the formula for DBELA is closer to the longitudinal $(x)$ direction of the building because this formula has been derived considering 2D frames, and in the nonseismically designed buildings the frames are only included in the $x$ direction. The variation in the period of vibration of the random buildings generated by Verderame et al. [27] was found to be larger than that from SP-BELA; this increase in variability is most likely due to the changes in plan dimensions considered by Verderame et al. [27], whilst in the SP-BELA calculations herein the number of bays has been kept constant in each direction.

The mean yield displacement capacity of the randomly generated buildings has been calculated using DBELA and SP-BELA for the $x$ and $y$ directions of the building, as presented in Figures 12 and 13, respectively. The coefficient of variation of the displacement capacity was found to be $36 \%$ for DBELA and just 13\% for SP-BELA. The larger variability in DBELA is due to the larger number of random variables used to describe the geometry of the building.

For the DBELA calculations, the beam- and columnsway displacement capacities are shown separately whilst the calculations for SP-BELA implicitly take into account the proportion of buildings which have each of these mechanisms, hence it is difficult to compare the results of the two methods without considering first the mechanism. The proportion of beam and column-sway mechanisms obtained for the random population of buildings in the SPBELA calculations is presented in Figure 14. The low-rise frames are seen to have a predominantly column-sway (i.e., strong beam-weak column) mechanism in both the $x$ and $y$ directions of the building. The mid-to-high rise buildings have a mixture of beam- and column-sway mechanisms, with a higher proportion of beam-sway mechanisms in the $x$ direction of the building. For low rise buildings, the ratio of beam-sway to column-sway mechanisms increases in the $x$ direction with the lateral design force because an increased lateral load means the buildings are designed to have larger column dimensions and thus are less likely to fail in a column-sway mechanism. This behaviour is less apparent in the $y$ direction as often the columns are placed with the longer dimension in the $x$ direction of the building (see Table 1). On the other hand, this trend is inverted in the high-rise buildings. As discussed in Borzi et al. [6], this effect is due to the fact that by increasing the lateral load coefficient " $c$," the required increase of the beam resistance leads to emergent beams (as opposed to embedded beams which are used in the design of the low-rise buildings) and this increase occurs at a higher rate than the increase of the column resistance. Hence, the high-rise buildings have stiff, strong beams, and a column-sway mechanism is thus more likely to occur.

4.3. Comparison between SP-BELA and DBELA. Considering that $100 \%$ of the 2 -storey building class with $5 \%$ lateral force design have a column-sway mechanism, and almost $100 \%$ of the 8 -storey building class with $5 \%$ lateral force design have a beam-sway mechanism in the $x$ direction, the capacities employed in DBELA for a column- and beam-sway mechanism, respectively, have been compared with those of SP-BELA for these classes only (see Table 4).

Such comparison is valid since the influence due to the failure mechanism has been removed, and thus some thought can be given to the differences in the two methodologies 


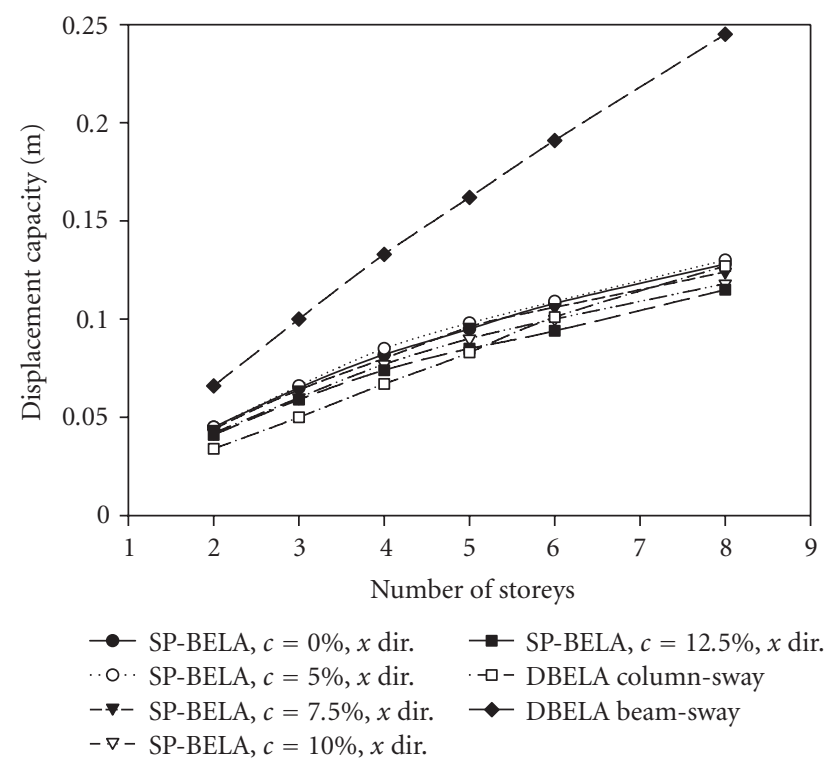

Figure 12: Mean yield displacement capacity versus number of storeys for the beam- and column-sway cases of DBELA compared with each of the SP-BELA design categories in the $x$ direction.

related to structural properties such as the displacement capacity and the period of vibration. The higher limit state properties in terms of displacement capacity and period of vibration are also considered here for the first time.

Table 4 shows that for the 2-storey building class, the values of displacement capacity and period of vibration are larger for SP-BELA whilst the collapse multiplier is lower. The difference in displacement capacity is due to the different displacement capacity predicted for columnsway frames in the two methods (see Section 3.3) but this is further amplified by the difference in the column dimensions assumed in DBELA and those assigned during the design for SP-BELA. In DBELA, due to a lack of data, the column dimensions have not been assumed to vary for each number of storeys, and instead a large coefficient of variation has been applied. In SP-BELA, each random building is designed and thus the column dimension changes depending on the numbers of storeys and the proportion of lateral force. The yield period of vibration predicted with DBELA has already been seen to be underestimated for low-rise seismically designed buildings (see Figure 8). As expected, the higher yield stiffness and lower yield displacement capacity predicted with DBELA lead to a higher strength.

For the 8-storey building, DBELA predicts higher yield displacement capacity and yield period of vibration, and thus lower lateral strength. The limit state displacement capacity for SP-BELA uses the column yield curvature, as shown in (11), whilst the DBELA equation for this building class uses the beam yield curvature. The yield curvature is inversely proportional to the section depth (e.g., [12]) and thus with larger column dimensions (that are used in this high, seismically designed building), the column yield curvature will be lower than the beam curvature; this explains the lower displacement capacities in SP-BELA. It is

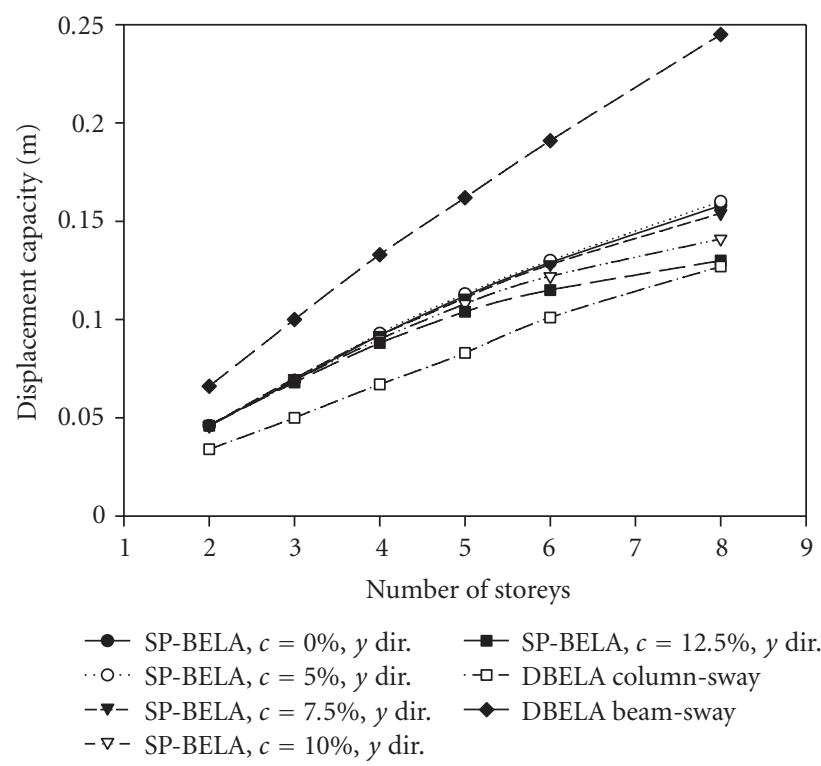

FIGURE 13: Mean yield displacement capacity versus number of storeys for the beam- and column-sway cases of DBELA compared with each of the SP-BELA design categories in the $y$ direction.

clear that further comparisons with nonlinear finite elements models of high-rise buildings are necessary to study whether the displacement capacity of beam-sway frames matches better the rotation capacity used in DBELA or in SP-BELA. The higher yield period of vibration predicted with DBELA for the 8-storey building follows the conclusions presented in the previous section (see Figure 8).

Another difference which is apparent from Table 4 is the larger variability in the DBELA results compared to the SPBELA results. As mentioned previously, this variability is due to the larger number of variables to describe the geometry of the building (i.e., beam and column dimensions) and the variance assigned to each of these variables in DBELA.

As mentioned in the Introduction, the focus of this paper is not on verifying the vulnerability estimates themselves, but the structural characteristics predicted with the two methodologies. So far, it has been shown that the differences between the two analytical methods considered herein are limited when considering individual buildings for which the structural characteristics are well known. The application of the two methods to an urban population, however, leads to larger variations between the two methods caused by the limited knowledge in DBELA and the need to use input data based on statistical studies. The variability in the two methods could have been reduced if the statistics of the buildings designed with SP-BELA had been used in DBELA, however the idea herein has been to apply the two methods blindly, and not use one method to calibrate the other. The next section of the paper explores the influence of the differences between the two methods for an urban population, in terms of vulnerability curves. Both methods predict the proportion of buildings which exceed the limit state for a range of values of peak ground acceleration, 


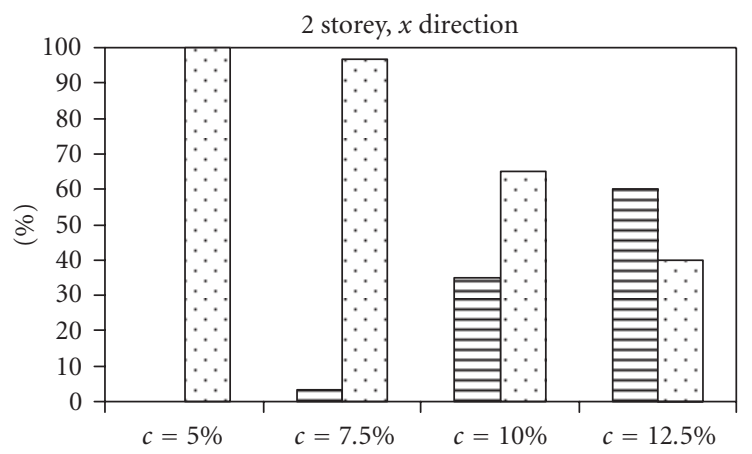

(a)

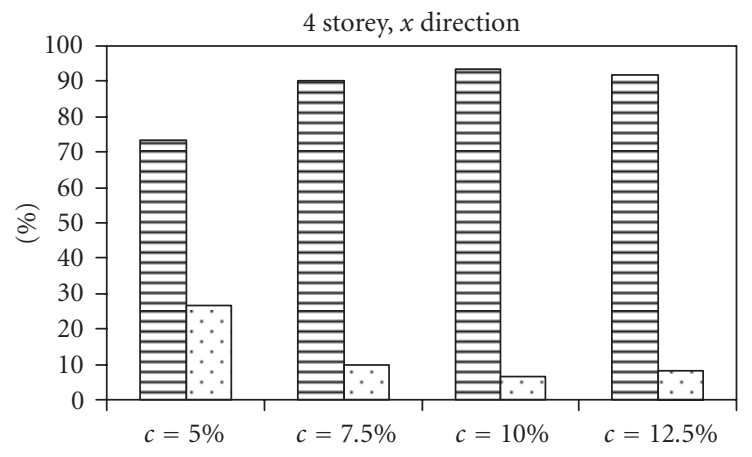

(c)

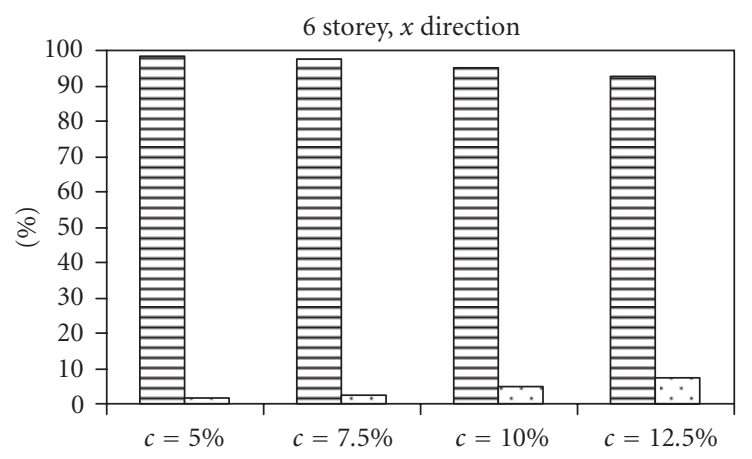

(e)

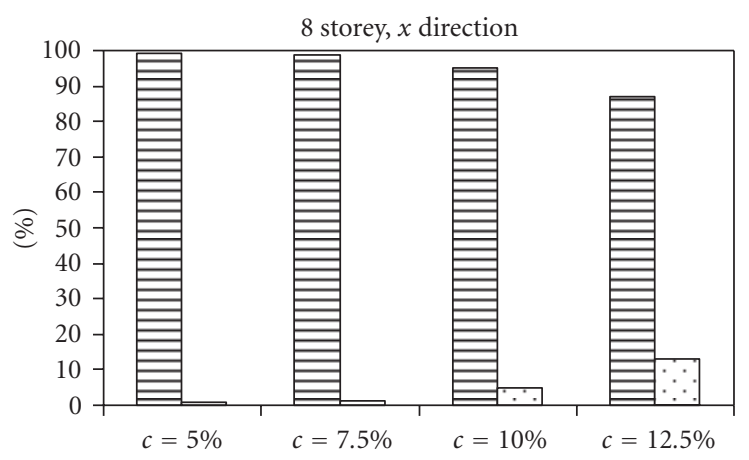

目 Beam sway

. Column sway

(g)

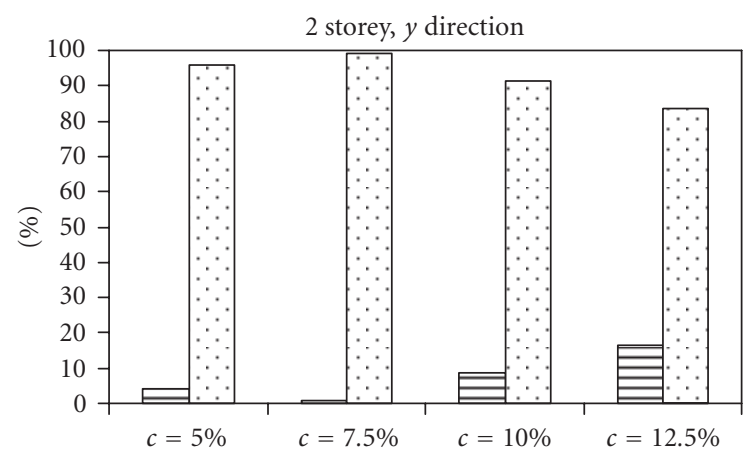

(b)

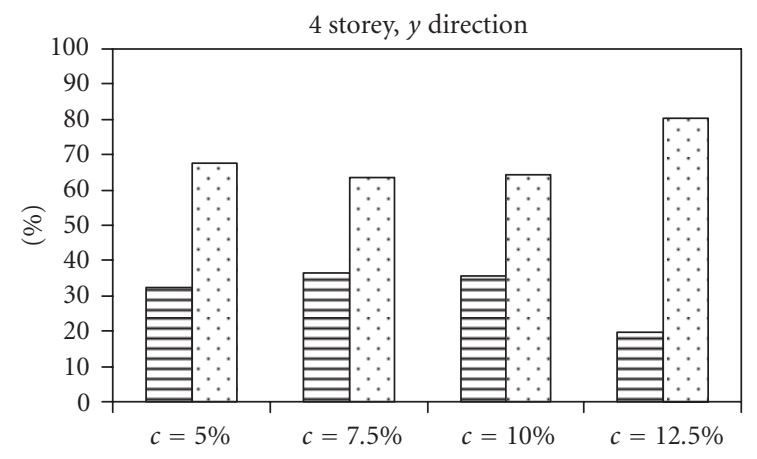

(d)

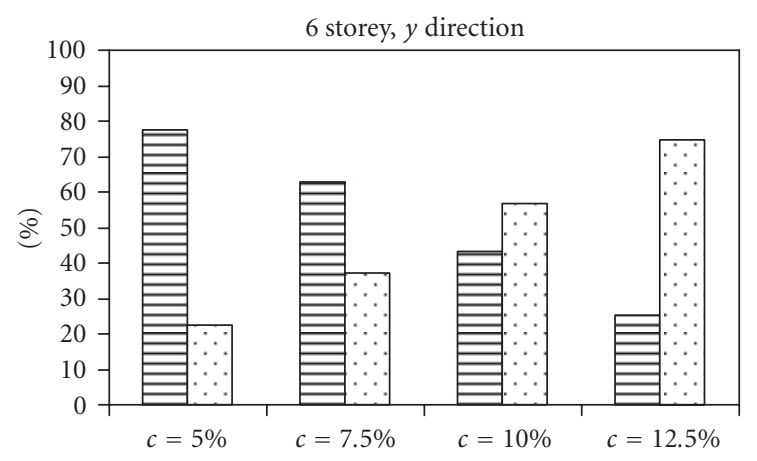

(f)

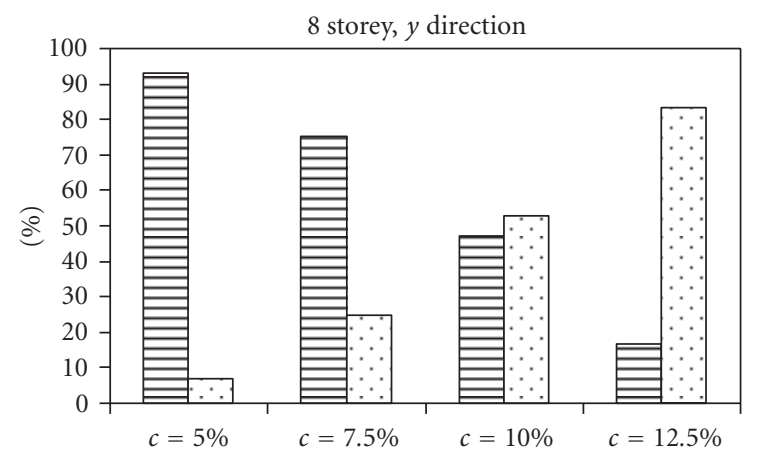

目 Beam sway

$\checkmark$ Column sway

FIGURE 14: Percentage of beam-sway and column-sway mechanisms in SP-BELA for the prototype building. 
SP-BELA

response and select a range of PGA values

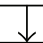

Randomly sample corner periods and variability of spectral amplification coefficient

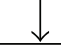

Generate a random population of spectral shapes
Choose prototype structure, deterministic parameters and design code

DBELA

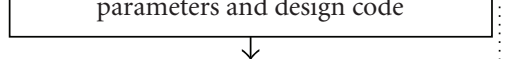

Randomly sample design loads, material properties, and geometrical properties
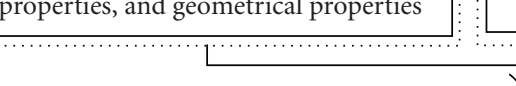

Randomly sample: error in period-height equation, material

properties, geometrical

properties and dimensions of structural elements

\section{$+$}

Generate a random building population

$(j=1, n)$

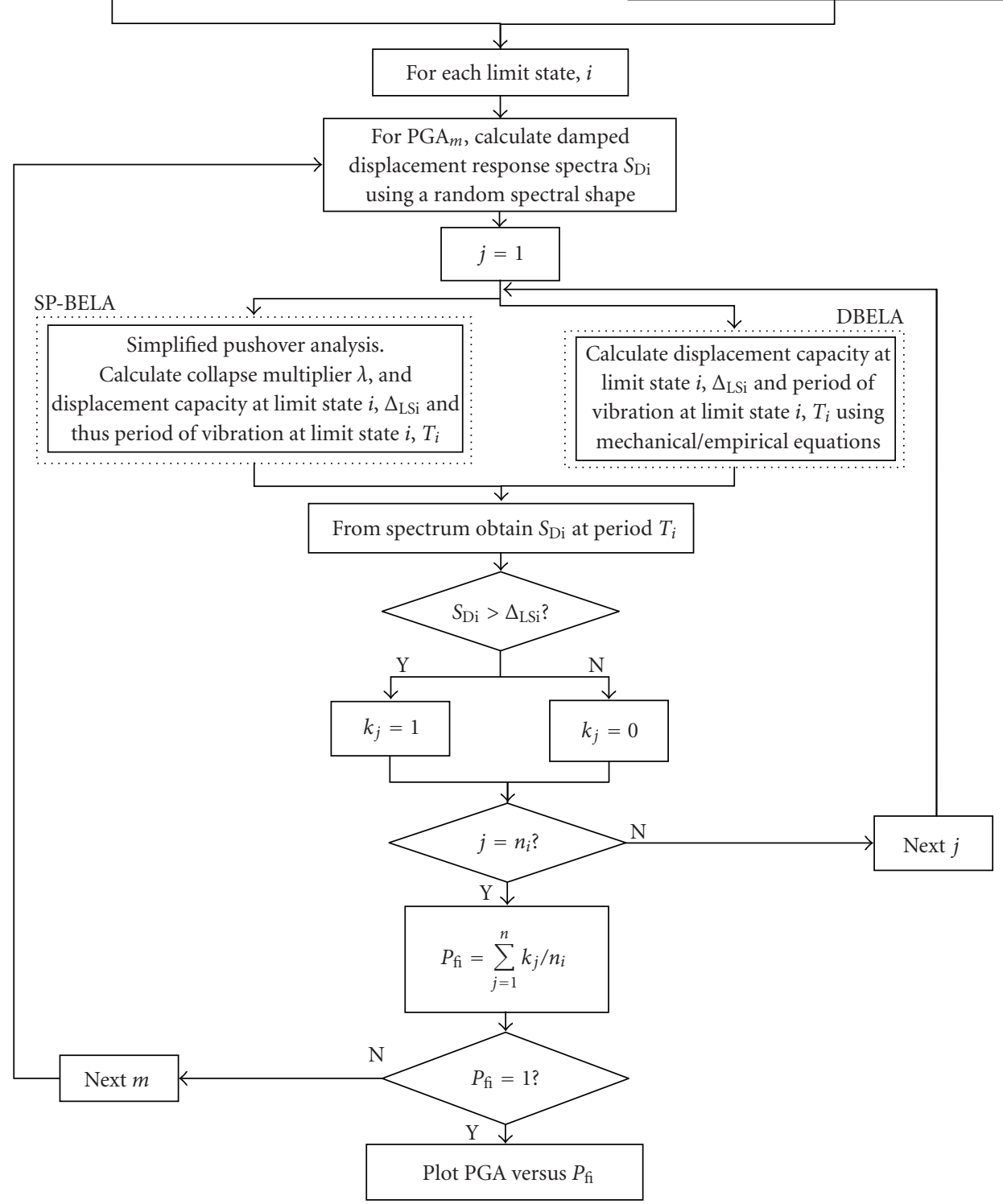

FIgURE 15: Flowchart of the DBELA and SP-BELA methodologies for the derivation of vulnerability curves for RC buildings.

with the most vulnerable direction of the building being considered in SP-BELA.

\section{Vulnerability Curves for Urban Populations}

Figure 15 presents the procedure considered herein for the comparison of the displacement capacity of the randomly generated buildings with the displacement demand using a displacement response spectrum: the random variables used to describe the variability of the spectrum are presented in Section 5.2. The differences in DBELA and SP-BELA for what concerns the generation of the random population of buildings and the calculation of the pushover curve are highlighted in Figure 15. It is noted that a preliminary 
TABLE 4: Comparison of periods of vibration, displacement capacity, and collapse multipliers in DBELA and SP-BELA (in $x$ direction).

\begin{tabular}{|c|c|c|c|c|c|}
\hline \multirow[b]{2}{*}{ Building class } & \multirow[b]{2}{*}{ Parameter } & \multicolumn{2}{|c|}{$\begin{array}{c}\text { SP-BELA, } x \text { direction } \\
\text { (Seismically designed, 5\%) }\end{array}$} & \multicolumn{2}{|c|}{ DBELA } \\
\hline & & $\mu$ & $\mathrm{CoV}$ & $\mu$ & $\mathrm{CoV}$ \\
\hline \multirow{7}{*}{2 storeys } & $T_{\mathrm{LS} 1}(\mathrm{~s})$ & 0.86 & $6 \%$ & 0.6 & $15 \%$ \\
\hline & $T_{\mathrm{LS} 2}(\mathrm{~s})$ & 1.14 & $9 \%$ & 0.78 & $25 \%$ \\
\hline & $T_{\mathrm{LS} 3}(\mathrm{~s})$ & 1.29 & $10 \%$ & 0.86 & $27 \%$ \\
\hline & $\Delta_{\mathrm{LS} 1}(\mathrm{~m})$ & 0.045 & $12 \%$ & 0.034 & $37 \%$ \\
\hline & $\Delta_{\mathrm{LS} 2}(\mathrm{~m})$ & 0.078 & $17 \%$ & 0.053 & $28 \%$ \\
\hline & $\Delta_{\mathrm{LS} 3}(\mathrm{~m})$ & 0.101 & $17 \%$ & 0.064 & $28 \%$ \\
\hline & $\lambda$ & 0.25 & $14 \%$ & 0.38 & $55 \%$ \\
\hline \multirow{7}{*}{8 storeys } & $T_{\mathrm{LS} 1}(\mathrm{~s})$ & 1.18 & $7 \%$ & 2.38 & $15 \%$ \\
\hline & $T_{\mathrm{LS} 2}(\mathrm{~s})$ & 1.65 & $10 \%$ & 2.99 & $25 \%$ \\
\hline & $T_{\mathrm{LS} 3}(\mathrm{~s})$ & 1.89 & $10 \%$ & 3.19 & $27 \%$ \\
\hline & $\Delta_{\mathrm{LS} 1}(\mathrm{~m})$ & 0.13 & $13 \%$ & 0.24 & $31 \%$ \\
\hline & $\Delta_{\mathrm{LS} 2}(\mathrm{~m})$ & 0.25 & $19 \%$ & 0.38 & $26 \%$ \\
\hline & $\Delta_{\mathrm{LS} 3}(\mathrm{~m})$ & 0.33 & $19 \%$ & 0.43 & $26 \%$ \\
\hline & $\lambda$ & 0.37 & $12 \%$ & 0.18 & $50 \%$ \\
\hline
\end{tabular}

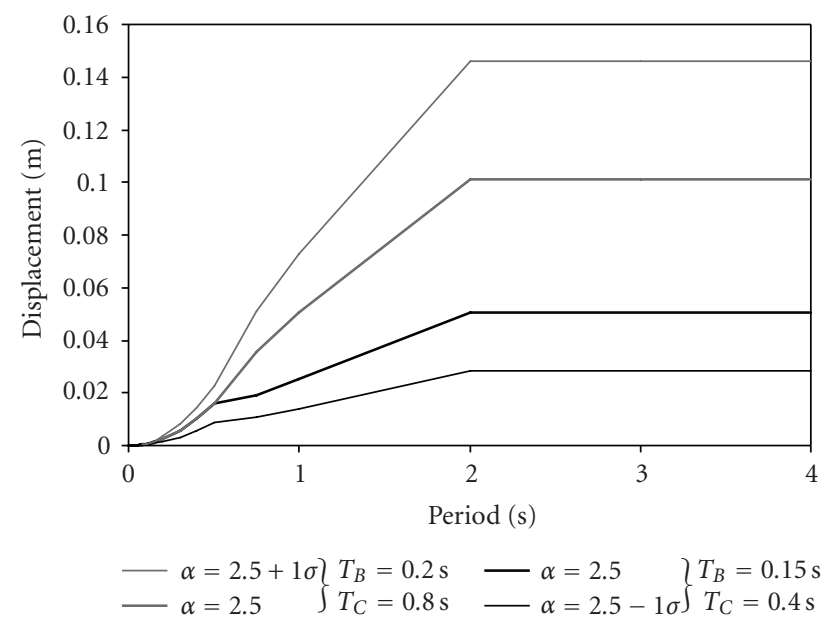

FIGURE 16: Upper and lower bound mean displacement spectral shapes due to variation of the characteristic periods (in bold). The thin lines show the upper bound spectrum $+1 \sigma$ and the lower bound spectrum $-1 \sigma$ that represents the variability in the coefficient $\alpha$.

comparison of the two methods based on vulnerability curves has been made in Borzi et al. [6].

5.1. Displacement Spectral Shape. A displacement spectral shape has been anchored to the PGA values for which the vulnerability is to be calculated. The spectral shape has been defined using the acceleration spectrum proposed by recent Italian regulations [19], multiplied by $(T / 2 \pi)^{2}$ where $T$ is the period of vibration, to give the displacement spectrum for $5 \%$ damping. This displacement spectra differs from that proposed in EC8 [25] because the displacement response does not reduce to the peak ground displacement at long periods, but remains constant after 2 seconds. The choice of a codified spectral shape has been made for the comparison of the two methodologies, but it would be just as feasible to use a displacement spectrum from a ground-motion prediction equation for a given scenario, or a uniform hazard spectrum from a probabilistic seismic hazard assessment.

Equivalent linearisation is currently applied to the structural model in both DBELA and SP-BELA, and thus the amount of energy that the system can dissipate is taken into account through the use of over-damped elastic response spectra (alternatively, and if preferred, it would be possible to employ constant-ductility spectra instead). The equivalent viscous damping $\xi_{\mathrm{LSi}}$ which quantifies the energy dissipated when the limit state $i$ is achieved, was calculated using the expression proposed by Calvi [7], though a wealth of other similar expressions available in the literature could also have been used (see, e.g., [31]):

$$
\xi_{\mathrm{LSi}}=a\left(1+\frac{1}{\mu_{\mathrm{LSi}}^{b}}\right)+\xi_{\mathrm{el}}
$$

where $\xi_{\mathrm{el}}$ is the damping ratio characterising the elastic response, commonly assumed as $5 \%$, and $a$ and $b$ are two coefficients that vary between 20 and 30 and 0.5 and 1 , respectively. In this application, $a=25$ and $b=0.5$.

The spectral reduction factor $\eta_{\mathrm{LS}}$, which is multiplied by the $5 \%$ damped displacement spectrum, can then be expressed as a function of the equivalent viscous damping defined above, as suggested in EC8 [25], though it is again noted that several other alternatives do exist in the literature (see, e.g., [31]):

$$
\eta_{\mathrm{LSi}}=\sqrt{\frac{10}{5+\xi_{\mathrm{LSi}}}}
$$


5.2. Random Variables to Describe Uncertainty in Displacement Demand. In the probabilistic procedure used to calculate the vulnerability curves, the uncertainty in the definition of the demand is accounted for by assuming the following.

(i) The corner periods of the spectrum are random variables having a constant distribution between the maximum and the minimum values (for $T_{B}$ the distribution is between 0.15 and 0.20 seconds and for $T_{C}$ the distribution is between 0.4 and 0.8 seconds).

(ii) The coefficient $\alpha$ (spectral amplification coefficient) has been taken as a random variable with a mean value of 2.5, a standard deviation of 1.1 , and a logarithmic distribution.

The sampling of random variables with a normal distribution to describe the uncertainty in the displacement demand has been generated using the Latin Hypercube algorithm [29], as mentioned previously.

The upper and lower bound mean displacement spectral shapes due to the variation in the characteristic periods of the spectrum are shown in bold in Figure 16, for a PGA $=1 \mathrm{~g}$ and $\alpha=2.5$. The shape of the spectrum is assumed to vary uniformly between these two bounds. Further variability is incorporated due to the uncertainty in the spectral amplification factor; the upper bound plus 1 standard deviation and the lower bound spectrum minus 1 standard deviation are also shown in Figure 16 (thin lines).

5.3. Vulnerability Curves. Vulnerability curves have been produced for the 2-storey and 8-storey buildings designed to $5 \%$ lateral loads using both DBELA and SP-BELA, as presented in Figure 17.

For SP-BELA, the $x$ direction was found to be the most vulnerable direction of the building for both building classes. The DBELA vulnerability curves are presented for the column-sway mechanism for the 2-storey building class and the beam-sway mechanism for the 8-storey building class as these were the predominant mechanisms found by SP-BELA in this direction (see Figure 14). Hence, the only differences in the two methods are due to the different period and displacement capacity predictions, as studied for these two particular building classes in Section 4.2. Although rather different periods of vibration and displacement capacities were predicted by the two methods, it can be seen in Figure 17 that the vulnerability curves are rather similar.

The first comparison that can be made from Figure 17(a) is that DBELA vulnerability curves are flatter than the SPBELA curves. This is caused by the larger variability in DBELA due to the increased number of random variables; additional geometrical properties are included as random variables and the coefficient of variation of the period of vibration is higher as it is based on a wider range of types of frames.

As has been described in the previous section, higher periods and higher displacement capacities have been predicted in SP-BELA for the 2 storey building class (see Table 4). Considering that the displacement demand increases with period up to 2 seconds (as shown in
Figure 16), higher demands are predicted when the period of vibration is higher; however these higher demands are counterbalanced by the higher displacement capacities. Thus, it is not surprising that different predictions of the displacement capacity and period lead to similar predictions of vulnerability. For the 8-storey buildings, higher periods of vibration and displacement capacities have been predicted with DBELA. Hence, again the higher displacement demands in DBELA are compensated by the higher displacement capacities; however considering that the demand is constant after 2 seconds, the vulnerability is lower as can be clearly seen in Figure 17(b).

\section{Conclusions}

The mechanics of two analytical vulnerability assessment methods (DBELA and SP-BELA) have been compared in this paper in terms of periods of vibration/base shear capacities and displacement capacities. Both methods have been seen to match well the nonlinear static pushover of nonseismically and weakly seismically designed buildings carried out with a finite elements-based structural analysis package. SP-BELA was seen to be able to capture the nonlinear static response of a number of buildings designed to different lateral load forces due to the implicit consideration of the strength in the method. On the other hand, the DBELA method was seen to underestimate the strength of seismically designed buildings due to the use of an initial stiffness based on the regression analysis of nonseismically designed frames. Buildings designed to a lateral force-based procedure tend to have larger column and beam dimensions and are thus stiffer and stronger; it appears that further calibration of the DBELA equations for initial stiffness/period is required for Southern European seismically designed reinforced concrete frames.

The initial studies on the individual building have shown how SP-BELA defines with a higher degree of accuracy the building behaviour, though further analyses are necessary to ascertain which method leads to a closer prediction of the yield displacement capacity of buildings with different heights and section dimensions. However, it should be pointed out that the use of SP-BELA requires the building stock under consideration to have been legally designed following particular code provisions, though in many countries such an assumption may not be valid. Nevertheless, when one is confident in the use of a code-based approach another advantage of the SP-BELA procedure is that it implicitly accounts for the proportion of the existing building stock which will have either a beam- or column-sway mechanism (or a combination of the two). Considering the higher accuracy of the SP-BELA methodology, comparisons in terms of the period-height equation, the displacement capacity, and the response mechanism have been made at an urban scale with the more simplified method, DBELA.

The aforementioned comparisons have shown how there is a variation in the period of vibration in the two directions of the prototype building, and the DBELA period-height equation matches quite well the longitudinal $(x)$ direction of the nonseismically designed prototype building, as this is 

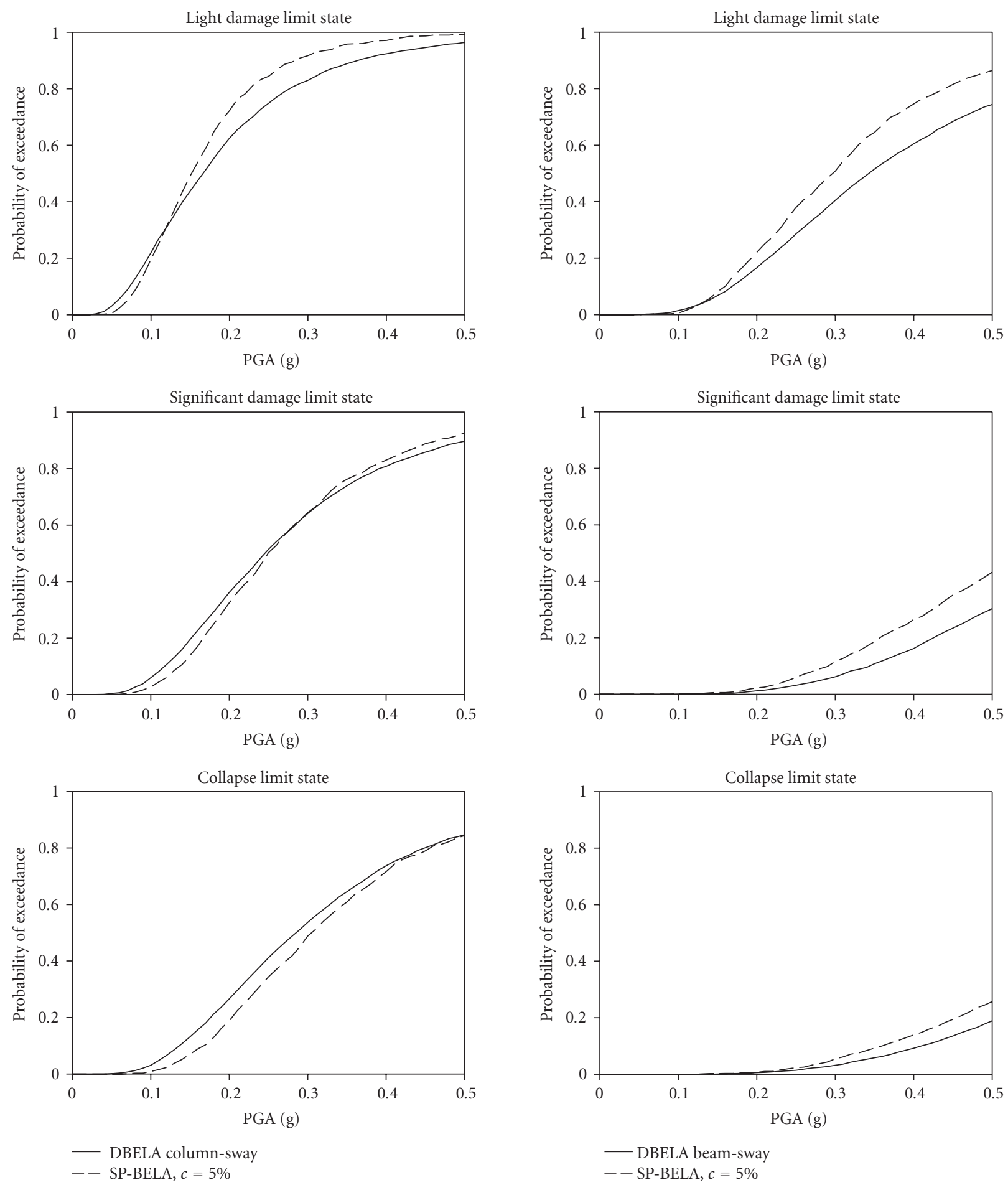

(a) 2 storeys

(b) 8 storeys

FIGURE 17: Vulnerability curves calculated with DBELA and SP-BELA for (a) 2-storey and (b) 8-storey buildings.

the direction in which the frames are placed. As mentioned previously, further calibration of the equation to match the seismically designed frames, as well as the transverse $(y)$ direction of the building, is necessary. The displacement capacity equations of the two methods are based on similar mechanics principles but on different definitions of the rotation capacity. Differences in the displacement capacity were thus seen to be quite large due to both the different equations used and the different section dimensions employed in the calculation of yield and ultimate curvatures. Furthermore, 
the displacement capacity in SP-BELA takes into account the proportion of each response mechanism whilst the DBELA equations are considered for each mechanism separately. Despite the differences in terms of displacement capacity and period of vibration, for building classes with a single dominant response mechanism, the two methods were seen to produce similar vulnerability curves. The similarities in the vulnerability predictions can be easily explained by comparing the relationship between the displacement demand in the two methods and the predicted displacement capacities.

To conclude, it can be stated that the results presented in this work are an initial step towards validating the adequacy and accuracy of the analytical vulnerability assessment methods discussed herein. This paper has highlighted how the difficulties in validating the latter through a comparison with actual observed damage data can begin to be overcome by comparing the results with those obtained from detailed nonlinear numerical structural models. Nonlinear dynamic analyses are currently being carried out such that further comparisons between the dynamic response of MDOF structures and the static response of the SDOF systems predicted by the two methods can be made, and the influence of higher mode effects, cyclic degradation of members, and so forth can be explicitly accounted for.

\section{Acknowledgments}

The authors would like to acknowledge the support of the Italian Ministry of Research and Higher Education (MIURMinistero dell'Università e della Ricerca) through the financing of the project Advancing Interdisciplinary Research PLAtform on volcanoes aNd Earthquakes (AIRPLANE).

\section{References}

[1] G. M. Calvi, R. Pinho, G. Magenes, J. J. Bommer, L. F. Restrepo-Velez, and H. Crowley, "The development of seismic vulnerability assessment methodologies for variable geographical scales over the past 30 years," ISET Journal of Earthquake Technology, vol. 43, no. 3, 2006.

[2] M. Colombi, B. Borzi, H. Crowley, M. Onida, F. Feroni, and R. Pinho, "Deriving vulnerability curves using Italian earthquake damage data," Bulletin of Earthquake Engineering. In press.

[3] A. Kappos, V. Lekidis, G. Panagopoulos, et al., "Analytical estimation of economic loss for buildings in the area struck by the 1999 Athens earthquake and comparison with statistical repair costs," Earthquake Spectra, vol. 23, no. 2, pp. 333-355, 2007.

[4] H. Crowley, P. J. Stafford, and J. J. Bommer, "Can earthquake loss models be validated with field observations?" Journal of Earthquake Engineering. In press.

[5] H. Crowley, R. Pinho, and J. J. Bommer, "A probabilistic displacement-based vulnerability assessment procedure for earthquake loss estimation," Bulletin of Earthquake Engineering, vol. 2, no. 2, pp. 173-219, 2004.

[6] B. Borzi, R. Pinho, and H. Crowley, "Simplified pushoverbased vulnerability analysis for large-scale assessment of RC buildings," Engineering Structures, vol. 30, no. 3, pp. 804-820, 2008.
[7] G. M. Calvi, "A displacement-based approach for vulnerability evaluation of classes of buildings," Journal of Earthquake Engineering, vol. 3, no. 3, pp. 411-438, 1999.

[8] M. J. N. Priestley, Myths and Fallacies in Earthquake Engineering, Revisited, The Mallet Milne Lecture, IUSS Press, Pavia, Italy, 2003.

[9] H. Crowley and R. Pinho, "Period-height relationship for existing European reinforced concrete buildings," Journal of Earthquake Engineering, vol. 8, no. 1, pp. 93-119, 2004.

[10] H. Crowley and R. Pinho, "Simplified equations for estimating the period of vibration of existing buildings," in Proceedings of the 1st European Conference of Earthquake Engineering and Seismology, Geneva, Switzerland, September 2006, paper no. 1122.

[11] H. Crowley, Periods of vibration for displacement-based assessment of RC buildings, M.S. dissertation, European School for Advanced Studies in Reduction of Seismic Risk (ROSE School), Pavia, Italy, 2003.

[12] M. J. N. Priestley, "Displacement-based seismic assessment of reinforced concrete buildings," Journal of Earthquake Engineering, vol. 1, no. 1, pp. 157-192, 1997.

[13] A. Masi, "Seismic vulnerability assessment of gravity load designed R/C frames," Bulletin of Earthquake Engineering, vol. 1, no. 3, pp. 371-395, 2003.

[14] E. Cosenza, G. Manfredi, M. Polese, and G. M. Verderame, "A multilevel approach to the capacity assessment of existing RC buildings," Journal of Earthquake Engineering, vol. 9, no. 1, pp. 1-22, 2005.

[15] I. Iervolino, G. Manfredi, M. Polese, G. M. Verderame, and G. Fabbrocino, "Seismic risk of R.C. building classes," Engineering Structures, vol. 29, no. 5, pp. 813-820, 2007.

[16] G. Di Pasquale, A. Fralleone, A. G. Pizza, and C. Serra, "Synthesis of the code evolution from the Royal Decree issued after the Messina and Reggio earthquake up to the first Ministry decree issued after the Messina and Reggio earthquake up to the first decree issued after the law n. 64/74," in La Classificazione e la Normative Sismica Italiana dal 1909 al 1984, R. De Marco and M. G. Martini, Eds., Istituto Poligrafico e Zecca dello Stato, Roma, Italy, 1999.

[17] G. Di Pasquale, A. Fralleone, A. G. Pizza, and C. Serra, "Relevant changes to the Italian seismic code from 1909 to 1975-a synoptic table," in La Classificazione e la Normative Sismica Italiana dal 1909 al 1984, R. De Marco and M. G. Martini, Eds., Istituto Poligrafico e Zecca dello Stato, Roma, Italy, 1999.

[18] T. Panagiotakos and M. N. Fardis, "Deformation of R.C. members at yielding and ultimate," ACI Structural Journal, vol. 98, no. 2, pp. 135-148, 2001.

[19] Ordinanza del Presidente del Consiglio dei Ministri n, 3274 del 20 Marzo 2003, "Primi elementi in materia di criteri generali per la classificazione sismica del territorio nazionale e di normative tecniche per le costruzioni in zona sismica," GU n, 72 del June 2003.

[20] Decreto Ministeriale 14 febbraio 1992, "Norme tecniche per l'esecuzione delle opere in cemento armato normale e precompresso e per le strutture metalliche," 1992.

[21] SeismoSoft, "SeismoStruct-a computer program for static and dynamic analysis for framed structures," http://www.seismosoft.com/.

[22] M. A. López-Menjivar, Verification of a displacement-based Adaptive Pushover method for assessment of 2-D reinforced concrete buildings, Ph.D. thesis, European School for Advances Studies in Reduction of Seismic Risk (ROSE School), University of Pavia, Pavia, Italy, 2004. 
[23] C. Casarotti and R. Pinho, "Seismic response of continuous span bridges through fiber-based finite element analysis," Earthquake Engineering and Engineering Vibration, vol. 5, no. 1, pp. 119-131, 2006.

[24] M. J. N. Priestley, G. M. Calvi, and M. J. Kowalsky, Displacement-Based Seismic Design of Structures, IUSS Press, Pavia, Italy, 2007.

[25] CEN - Comite Europeen de Normalisation, "Eurocode 8, design of structures for earthquake resistance-part 1: general rules, seismic actions and rules for buildings," Pr-EN 1998-1. Final Draft. December 2003.

[26] S. Glaister and R. Pinho, "Development of a simplified deformation-based method for seismic vulnerability assessment," Journal of Earthquake Engineering, vol. 7, no. 1, pp. 107-140, 2003.

[27] G. M. Verderame, I. Iervolino, C. Meriniello, and G. Manfredi, "Il periodo nella valutazione sismica di edifici esistenti in c.a.," in Proceedings of the 12th Convegno L'Ingegneria Sismica in Italia, Pisa, Italy, June 2007.

[28] M. J. N. Priestley, F. Seible, and G. M. Calvi, Seismic Design and Retrofit of Bridges, John Wiley \& Sons, New York, NY, USA, 1996.

[29] J. C. Helton and F. J. Davis, "Latin hypercube sampling and the propagation of uncertainty in analyses of complex systems," Reliability Engineering \& System Safety, vol. 81, no. 1, pp. 2369, 2003.

[30] S. Marino, Rilievo ed elaborazione statistiche delle caratteristiche di edifici esistenti in cemento armato ai fini della valutazione di scenari di danno, Undergraduate thesis, Department of Structural Mechanics, University of Pavia, Pavia, Italy, 2005.

[31] E. Miranda and J. Ruiz-García, "Evaluation of approximate methods to estimate maximum inelastic displacement demands," Earthquake Engineering and Structural Dynamics, vol. 31, no. 3, pp. 539-560, 2002. 

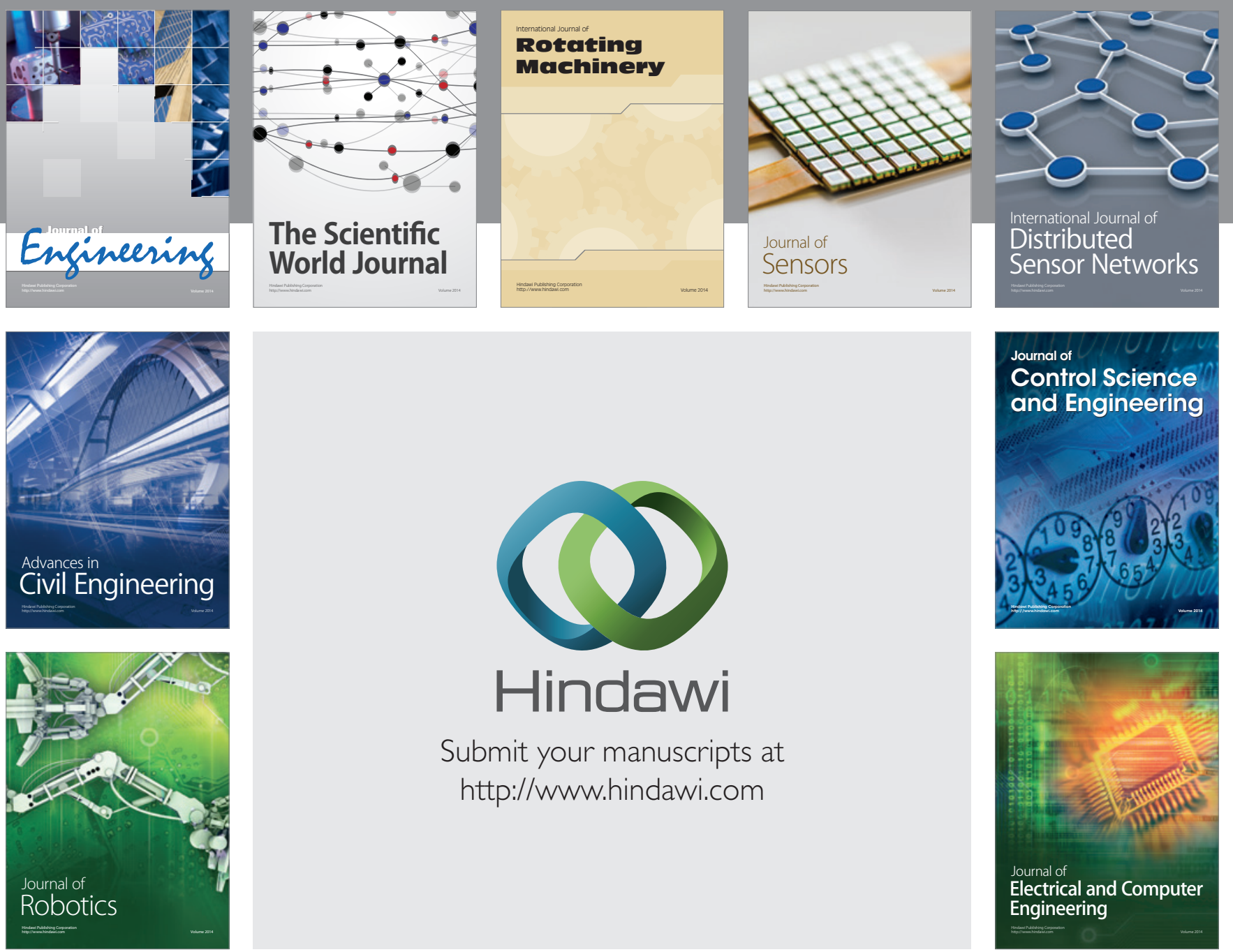

Submit your manuscripts at

http://www.hindawi.com
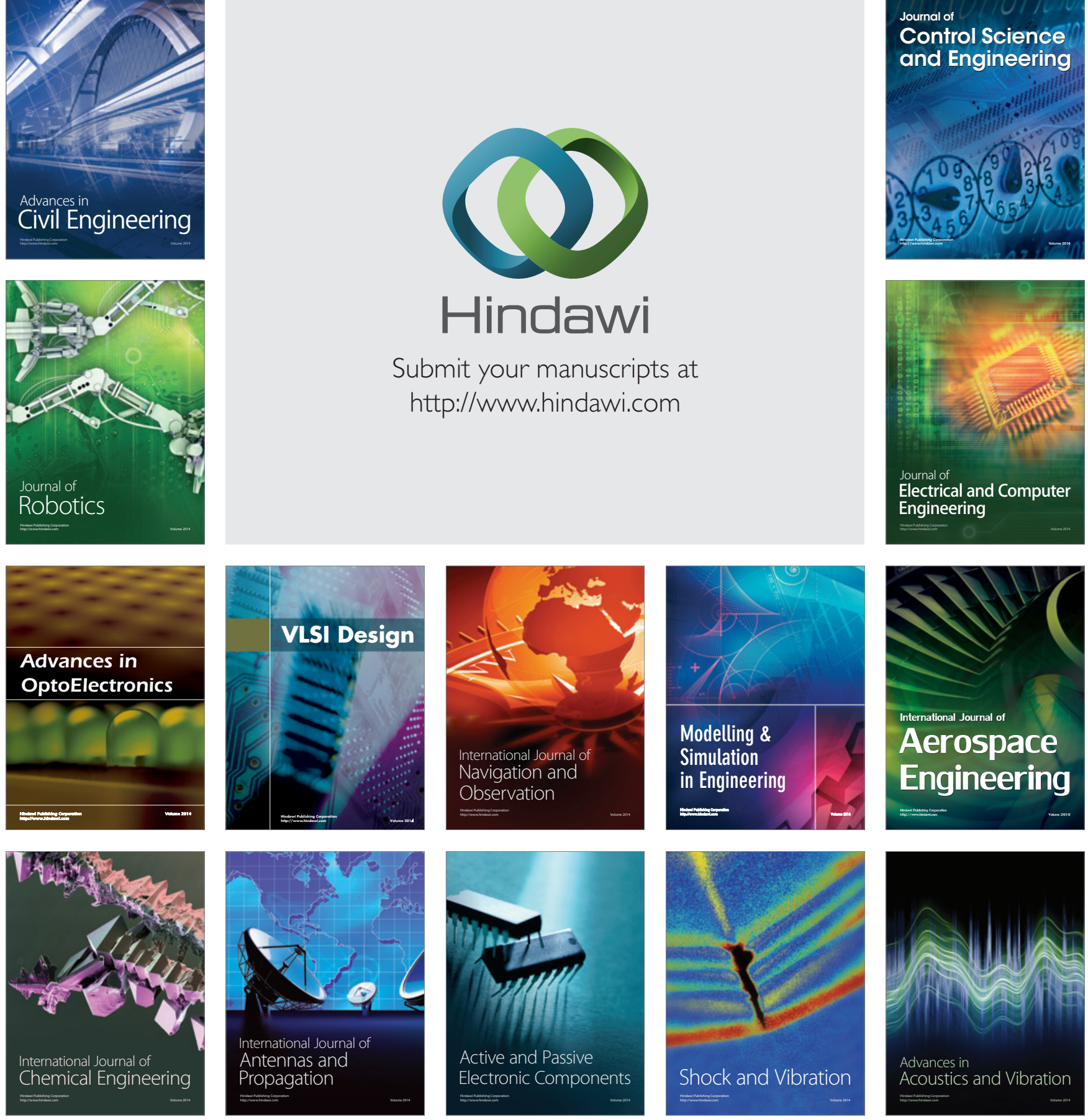